\title{
Prediction of sediment transport in step-pool channels
}

\author{
E. M. Yager, ${ }^{1}$ W. E. Dietrich, ${ }^{2}$ J. W. Kirchner, ${ }^{2,3}$ and B. W. McArdell ${ }^{3}$ \\ Received 19 April 2011; revised 14 September 2011; accepted 13 December 2011; published 27 January 2012.
}

[1] In mountainous drainage networks, sediment mobilized on hillslopes must first pass through steep streams before reaching lower-gradient channels. The bed of steep channels is typically composed of large, relatively immobile boulders and finer, more mobile gravel. Most sediment transport equations overpredict sediment flux in steep streams by several orders of magnitude because they do not account for the stress borne by immobile grains and the limited availability of the more mobile sediment. We previously developed and tested (in flume experiments) a sediment transport equation that accounts for these two effects. Here we modify the Parker (1990) bed load equation to include the resistance borne by steps and selective transport of the relatively mobile sediment using a range of hiding functions. We test a number of resistance equations and hiding functions, combined with our modified and the original Parker equations, against measured flow and sediment transport in three steep channels. Our modified sediment transport equation generally predicts the transported sediment volumes to within an order of magnitude of the measured values, whereas the unmodified equations do not. The most accurate sediment flux predictions were obtained from using our modified equation, combined with a hiding function that calculates highly selective transport of the relatively mobile sediment. Furthermore, this hiding function has a critical Shields stress that is similar to those reported for lower gradient channels. The effects of the immobile steps on flow and sediment transport are not adequately captured by simply increasing the critical Shields stress to values reported in steep streams.

Citation: Yager, E. M., W. E. Dietrich, J. W. Kirchner, and B. W. McArdell (2012), Prediction of sediment transport in step-pool channels, Water Resour. Res., 48, W01541, doi:10.1029/2011WR010829.

\section{Introduction}

[2] In mountainous drainage basins, the majority of small tributaries are steep, rough-bedded streams that directly border hillslopes and receive sediment prior to other channels in the network. Thus, steep streams partially dictate the timing and magnitude of sediment delivery to downstream, lower-gradient channels. To accurately predict future changes in river systems, calculations of sediment routing [e.g., Benda and Dunne, 1997; Ferguson et al., 2006; Sklar et al., 2006] and landscape evolution [e.g., Howard et al., 1994; Tucker and Whipple, 2002] must include sediment transport processes in steep channels. In very steep channels $(>\sim 10 \%)$, periodic debris flows cut bedrock channels and may primarily control sediment transport [e.g., Stock and Dietrich, 2003] although fluvial processes still dominate sediment transport in some streams [Rickenmann, 1997; D'Agosinto and Lenzi, 1999; Turowski et al., 2009]. Both of these sediment transport

\footnotetext{
${ }^{1}$ Center for Ecohydraulics Research, Civil Engineering Department, University of Idaho, Boise, Idaho, USA.

${ }^{2}$ Earth and Planetary Science Department, University of California at Berkeley, California, USA.

${ }^{3}$ Swiss Federal Institute for Forest, Snow and Landscape Research (WSL).
}

Copyright 2012 by the American Geophysical Union 0043-1397/12/2011WR010829 processes in steep streams are poorly understood but here we limit our discussion to fluvial bed load transport. Bed load transport equations developed for lower-gradient channels typically overpredict fluvial sediment transport rates in steep streams by several orders of magnitude [e.g., Bathurst et al., 1987; Rickenmann, 1997; D'Agostino and Lenzi, 1999; Yager et al., 2007; Mueller et al., 2008]. Such equations do not perform well in steep streams because these channels differ from lower-gradient reaches in several ways.

[3] Steep streams have wide grain-size distributions that include finer, more mobile sediment and large, relatively immobile grains (Figure 1). The large grains are typically arranged into cascades or steps, which protrude through the flow surface during sediment transport events. Thus, large grains increase flow resistance [e.g., Bathurst, 1985; Wiberg and Smith, 1991; Marcus et al., 1992] and cause deviations from the commonly assumed logarithmic velocity profile [Wiberg and Smith, 1991; Byrd and Furbish, 2000; Byrd et al., 2000; Wohl and Thompson, 2000]. Commonly used resistance equations do not accurately predict flow depth and shear stress in steep streams. Errors in shear stress are magnified in sediment transport predictions because sediment flux is typically assumed to increase nonlinearly with excess shear stress (shear stress minus critical shear stress, which is the stress needed to mobilize sediment). The dimensionless critical shear stress (critical shear stress normalized by grain weight, see equation (A5) in the 


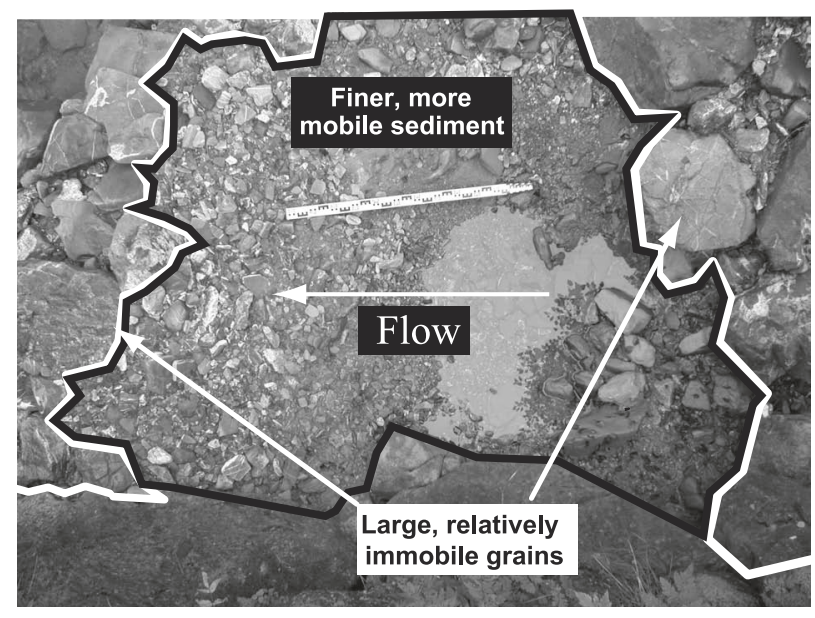

Figure 1. Photograph of the Erlenbach in Switzerland ( $\sim 4 \mathrm{~m}$ in length). The bed is composed of large, relatively immobile grains and finer, more mobile sediment.

appendix) may be relatively high in steep streams because of the effects of immobile particle resistance, grain interlocking, and decreased turbulence intensities in these channels [e.g., Bathurst et al., 1987; Buffington and Montgomery, 1997; Church and Zimmermann, 2007; Lamb et al., 2008; Mao et al., 2008].

[4] Many sediment transport equations also are based on the assumption that most grain sizes on the bed are potentially mobile. In steep streams, finer, more mobile sediment is transported over large, relatively immobile grains that rarely move [e.g., Lenzi et al., 1999; Garcia et al., 1999; Yager, 2006]. Sediment transport equations only perform moderately well in steep channels when all grain sizes, including the boulder steps, move during large floods [Bathurst et al., 1987; Rickenmann, 1997; D'Agostino and Lenzi, 1999]. In addition, these equations are based on the assumption of an unlimited availability of bed sediment for transport, although the sediment supply may be highly episodic from infrequent landslides and debris flows [e.g., Bathurst et al., 1986; Benda and Dunne, 1997].

[5] Yager et al. [2007] developed a sediment transport equation that accounts for the effects of large, relatively immobile grains and limited sediment availability. This sediment transport equation predicted the sediment flux to within an order of magnitude of the measured values when tested in a steep laboratory flume [Yager et al., 2007]. Although it performed well in flume experiments, this equation has two assumptions that limit its application in natural streams. It does not account for partial and size selective transport, which occur in steep streams [Lenzi et al., 1999; Garcia et al., 1999; Lenzi, 2001, 2004; Mao et al., 2008; Yager, 2006]. During partial transport, a portion of the grain-size distribution, usually the coarse grains, remains immobile whereas selective transport denotes a bed load grain-size distribution that is typically finer than that of the bed (following the definitions by Parker [2008]). The sediment transport equation of Yager et al. [2007] also represents the relatively immobile grains as isolated roughness elements with a characteristic spacing, and is only applicable for cascade channels. In many steep streams, immobile grains are clustered into steps that span a large portion of the channel width.

[6] Here we modify the sediment transport equation of Yager et al. [2007] to include the effects of immobile-grain steps and selective transport. We then test a number of sediment transport equations and hiding functions using measured sediment flux events in two well- instrumented steep streams. Sediment transport predictions in these streams are reasonably accurate if they include the effects of immobile grains and the limited availability and selective transport of the relatively mobile sediment. Independent modification of only hiding functions to indirectly account for the effects of the immobile grains does not significantly improve sediment flux predictions.

\section{Stress-Partitioning and Sediment Transport Equations}

[7] Yager et al. [2007] partitioned the total shear stress between the stresses borne by the immobile and mobile sediment. The large, immobile grains bear a significant fraction of the total shear stress $(\sim 50 \%$ in the Erlenbach, one of our field sites) and reduce the stress available to transport the finer, more mobile sediment. Yager et al. [2007] also assumed the portion of the bed covered by mobile sediment is a proxy for local sediment availability. They then developed a set of stress-partitioning and sediment transport equations for steep, rough streams. We modify these equations to include immobile-grain steps and selective transport of the relatively mobile sediment.

\subsection{Stress-Partitioning Calculation}

[8] Our stress-partitioning equations are similar to those used by Yager et al. [2007] and the changes are listed in the appendix. We divide the bed into two fractions: large, relatively immobile grains with a characteristic diameter (D) and finer, more mobile sediment (Figure 2). The immobile grains are closely packed in the cross-stream direction $\left(\lambda_{\mathrm{y}}=\mathrm{D}\right.$ in Figure 2) into steps that have an average downstream spacing of $\lambda_{\mathrm{x}}$ (Figure 2). Within a single step, we assume the more downstream immobile grains bear little drag because the upstream grains shelter them from the flow. We combine all grains within a step into one row of cylindrical immobile grains with an average downstream length $\left(\lambda_{\mathrm{w}}\right)$. We also average over the considerable variation in downstream step spacing [Zimmermann and Church, 2001] to make predictions at the reach scale.

[9] We partition the total boundary shear stress $\left(\tau_{\mathrm{t}}\right)$ between the stress on the immobile grains $\left(\tau_{\mathrm{I}}\right)$ and the stress on the mobile sediment $\left(\tau_{\mathrm{m}}\right)$. Plunging flow over steps (spill resistance) also dissipates considerable energy [Curran and Wohl, 2003; Wilcox et al., 2006], but spill resistance equations currently lack field calibration and use many parameters [e.g., Moore, 1943; Rouse, 1943; Gill, 1979; Rajaratham and Chamani, 1995; Hoffman, 1998; James et al., 2001]. Such parameters require detailed empirical calibration that is beyond the scope of our study. Therefore, we assume spill resistance influences the pressure and velocity distributions around immobile grains and incorporate it into the drag coefficient of these particles. 
(a)

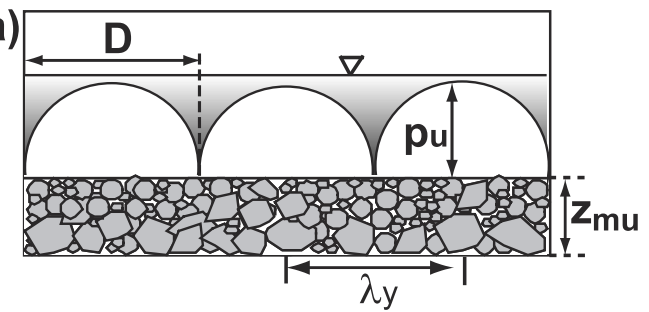

(b)

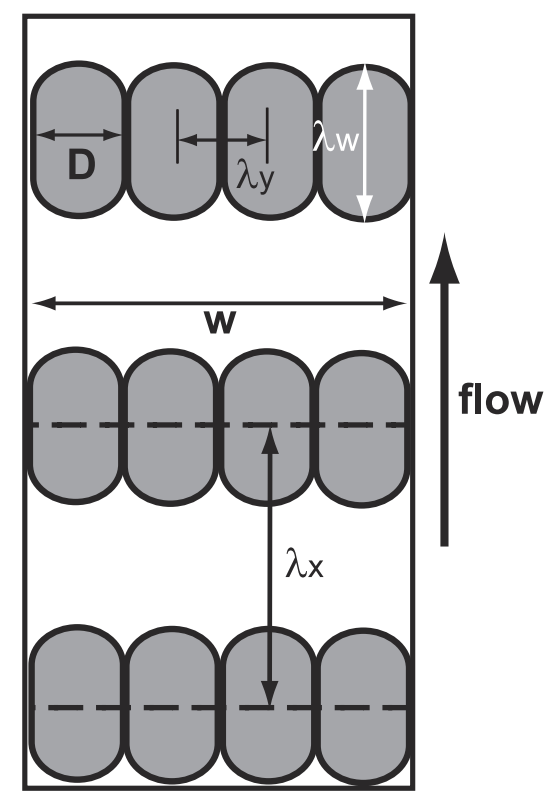

Figure 2. The (a) cross-sectional and (b) plan view of the bed configuration used in the stress-partitioning equations. $\mathrm{w}$ is the channel width and $\mathrm{z}_{\mathrm{mu}}$ is the reach-averaged, bedperpendicular height of the mobile sediment immediately upstream of the steps. This is the depth of sediment that partially buries the immobile grains. The immobile grains have a characteristic diameter (D), upstream protrusion $\left(\mathrm{p}_{\mathrm{u}}\right)$, downstream length $\left(\lambda_{\mathrm{w}}\right)$, downstream spacing $\left(\lambda_{\mathrm{x}}\right)$, and cross-stream spacing $\left(\lambda_{\mathrm{y}}\right)$.

[10] The solution to our stress-partitioning equations (see the appendix for details) is given by

$$
\mathrm{q}=\sqrt{\frac{2 \mathrm{gS} \lambda_{\mathrm{x}} \mathrm{h}_{\mathrm{a}}^{3}}{\frac{\mathrm{A}_{\mathrm{IF}} \mathrm{C}_{\mathrm{I}}}{\mathrm{w}}+\mathrm{C}_{\mathrm{m}}\left(\lambda_{x}-\lambda_{w}\right)}},
$$

where $\mathrm{q}$ is discharge per unit width, $\mathrm{h}_{\mathrm{a}}$ is reach-averaged flow depth, $\mathrm{g}$ is gravitational acceleration, $\mathrm{w}$ is channel width, $\mathrm{S}$ is reach-averaged water-surface slope, $\mathrm{A}_{\mathrm{IF}}$ is the total bed-perpendicular area occupied by immobile grains, and $\mathrm{C}_{\mathrm{m}}$ and $\mathrm{C}_{\mathrm{I}}$ are drag coefficients for the mobile and immobile sediment, respectively. The distance from the top of the average sediment (both mobile and immobile) deposit to the water surface $\left(h_{a}\right)$ includes the flow between and over immobile grains and steps.

[11] We calculate $h_{a}$ for a given flow discharge using equation (1) and an equation for $\mathrm{A}_{\mathrm{IF}}$ (see equation (A4) in the Appendix), which is a function of $h_{a}$ and the bedperpendicular height of the mobile sediment that is directly upstream of steps $\left(z_{m u}\right.$, Figure 2$)$. This height represents the degree of step burial by relatively mobile sediment and is calculated by measuring the upstream protrusion of the immobile steps (averaged over the reach, see section 3.1.2) and subtracting it from $D$. To calculate $h_{a}$ using equations (1) and (A4), we must iterate the value of $h_{a}$ until the predicted discharge from (1) equals the measured discharge. This combination of equations requires estimates of seven reach-averaged variables $\left(\mathrm{w}, \mathrm{S}, \mathrm{q}, \mathrm{D}, \mathrm{z}_{\mathrm{mu}}, \lambda_{\mathrm{x}}\right.$, and $\lambda_{\mathrm{w}}$ ), and two drag coefficients $\left(\mathrm{C}_{\mathrm{m}}\right.$ and $\left.\mathrm{C}_{\mathrm{I}}\right)$. Once we know $\mathrm{h}_{\mathrm{a}}$, we then calculate the total shear stress,

$$
\tau_{\mathrm{t}}=\rho \mathrm{gh}_{\mathrm{a}} \mathrm{S}
$$

where $\rho$ is the water density, and the stress borne by mobile sediment,

$$
\tau_{\mathrm{m}}=\frac{\rho \mathrm{C}_{\mathrm{m}} \mathrm{U}^{2}}{2}
$$

where $U$ is the reach-averaged flow velocity $\left(q / h_{a}\right)$.

[12] We use $h_{a}$ instead of the hydraulic radius (R) because the use of $\mathrm{R}$ would require that we partition the total shear stress between the walls and the immobile and mobile sediment. The addition of a wall resistance equation (see Buffington and Montgomery [1999a] for an example) makes our stress-partitioning equations underdetermined and unsolvable for most applications where only the flow discharge is known. To demonstrate that we can neglect wall roughness, we can solve the stress-partitioning equations that include wall roughness because we have measured the flow hydraulics $\left(\mathrm{h}_{\mathrm{a}}\right.$ and $\left.\mathrm{U}\right)$ in the Erlenbach torrent (see section 3.1.3). We used equation (15) from Buffington and Montgomery [1999a] in our stress-partitioning equations, and replaced $h_{a}$ with $R$ in equation (2), to estimate the percent of the total fluid force that could be attributed to wall roughness. The contribution of wall roughness varied between $1 \%$ of the total fluid force at base flow to a maximum of $4 \%$ during a flood with a $\sim 50$ yr recurrence interval. Thus, although steep channels may be relatively narrow, wall roughness may be neglected because its resistance contribution is small relative to that caused by steps and plunging flow.

\subsection{Prediction of Bed Load Transport Rates}

[13] Yager et al. [2007] modified the Fernandez Luque and Van Beek equation [Fernandez Luque and Van Beek, 1976] such that the sediment transport rate depends on: the stress on the mobile sediment rather than the total shear stress, the median grain size of the mobile sediment $\left(D_{50 \mathrm{~m}}\right)$ rather than that of the entire bed, and the proportion of the bed occupied by mobile sediment $\left(\mathrm{A}_{\mathrm{m}} / \mathrm{A}_{\mathrm{t}}\right)$ to account for sediment availability. Their equation does not allow for partial and selective transport of sediment, which occur in many steep streams [e.g., Garcia et al., 1999; Lenzi, 2004; Ryan et al., 2005; Lenzi et al., 2006; Mao et al., 2008; Yager, 2006]. We therefore used the surface-based sediment transport equations of Parker [1990] to calculate selective transport (see the appendix for original equations). Sand is assumed to be a relatively minor fraction of the bed load, and we did not estimate its fraction of the bed surface and neglect it here.

[14] We modified the Parker [1990] equations such that they depend on: the stress borne by the mobile sediment 
instead of the total shear stress, the grain-size distribution of the relatively mobile sediment instead of that of the entire bed, and the fraction of the bed surface that is covered by mobile sediment $\left(A_{m} / A_{t}\right)$. Details on this modification are provided in the appendix. The modified equations require predicted values of $\tau_{\mathrm{m}}$ (from equation (3)), and measured values of $A_{m} / A_{t}$ and the grain-size distribution of the relatively mobile sediment. If the bed is divided into patches of sediment, a composite grain-size distribution for all relatively mobile patches is needed because the above equations use reach-averaged parameters for shear stress and grain size.

\section{Field Measurements}

[15] We used three different field locations (Fox Creek, and the Erlenbach and Rio Cordon torrents) to test our stress-partitioning and bed load transport equations. In the Erlenbach, we measured flow conditions and channel bed properties to calibrate the drag coefficients in our stresspartitioning equations. We also measured tracer particle movements to develop a calibrated hiding function for the Erlenbach. We then tested our combined stress-partitioning (calibrated to the Erlenbach) and bed load transport equations (using a range of hiding functions) against measured sediment transport volumes. In Fox Creek, we measured flow and bed properties to independently test our calibrated stress-partitioning equations and other resistance equations. Finally, in the Rio Cordon, we use previously published data on channel bed properties, flow hydrographs, and transported sediment volumes and grain sizes to test our combined stress-partitioning and bed load transport equations.

\subsection{Erlenbach}

[16] The Erlenbach torrent is a small (drainage area of $\left.0.74 \mathrm{~km}^{2}\right)$, steep (9.8\% gradient in our measurement reach) stream in Switzerland (Latitude of 47.0454, Longitude of 8.7082). The Swiss Federal Institute for Forest, Snow, and Landscape Research (WSL) has continuously monitored water discharge and sediment transport rates in the Erlenbach since 1978 and 1986, respectively [Hegg et al., 2006]. Snowmelt, rain-on-snow, and high-intensity summer storms cause about 20 sediment transport events each year [Rickenmann, 1997]. The average sediment yield in the Erlenbach is $\sim 570 \mathrm{~m}^{3} \mathrm{~km}^{-2} \mathrm{yr}^{-1}$ (volume includes porosity), which is a minimum estimate because the WSL only measures a portion of the suspended load.

\subsubsection{Sediment Transport Rates}

[17] Geophone-based bed load impact sensors, hereinafter called bed load sensors, record sediment transport rates in a cross section that is directly upstream from a sediment retention basin (see Rickenmann and McArdell [2007] for details). The total number of impulses, a measure of the energy imparted to the bed by impacting grains, by grains larger than $1 \mathrm{~cm}$ are recorded at minute intervals by the array of bed load sensors if the impulses exceed 4/min [Turowski and Rickenmann, 2011]. The bed load sensor impulses have been calibrated to annual or biannual sediment-volume changes in the retention basin [Rickenmann, 1997; Rickenmann and McArdell, 2007; Turowski and Rickenmann, 2011]. Twelve bed load sensors operated from 1986 to 1999 and then were replaced by nine new bed load sensors. Rickenmann and McArdell [2007] developed a calibration for events prior to 2002 and a similar unpublished calibration [J. M. Turowski and D. Rickenmann, pers. comm.] is available for events after 2002. Further information on the calibration and uncertainty of the bed load sensors is detailed by Rickenmann [1997], Rickenmann and McArdell [2007], and Turowski and Rickenmann [2011].

[18] The channel bed properties (protrusion, grain sizes) used in our transport predictions are sensitive to the relative sediment supply (see section 3.1.2). We therefore limited our analysis of sediment transport data to events between 2002 and 2006, which bracket our 2004 measurements of streambed characteristics by 2 years. The sediment yield from the Erlenbach was relatively constant over this time period and was much larger in the preceding and subsequent years [see Turowski et al., 2009]. We excluded any events with less than $3 \mathrm{~m}^{3}$ of transported sediment $(\sim 50 \%$ of the events during our analysis period) because the bed load sensor calibration was not developed for low sediment yield events [Rickenmann and McArdell, 2007; D. Rickenmann, personal communication]. We also limited our sediment flux predictions in each event to only include grain sizes larger than $1 \mathrm{~cm}$ because this is the smallest size that the bed load sensors can measure. We converted the measured transported volumes to the equivalent volumes predicted by bed load transport equations by including the effects of porosity, which we assumed to be $40 \%$.

[19] To test and calibrate our stress-partitioning and sediment transport equations, we supplemented the WSL's data with measurements of flow depth, flow velocity, and bed properties (width, slope, height of mobile sediment, grain sizes, and immobile-grain spacing).

\subsubsection{Bed Properties}

[20] Our 40-m long study reach was directly upstream of the bed load sensors and downstream from a tributary junction. We used a total station to measure the bed slope (0.098) along the thalweg and the outlines and elevations of patches (see Yager [2006] for a map of the patches). A given patch class was named by the grain sizes (gravel, cobble, boulder) present within the patch and each size was only included if it was more than $5 \%$ of the patch area. The grain sizes were listed in order of increasing frequency on a patch and the dominant size was capitalized (e.g., gravelCobble) [Buffington and Montgomery, 1999b]. We conducted at least one pebble-count (with $\geq 100$ grains) on each of seven patch classes and then divided all 63 identified patches into immobile steps or relatively mobile sediment. The pebble counts were primarily through the grid method, in which the grid spacing was defined by the grain size on each patch. We measured all boulders and large cobbles in every step to obtain enough measurements (134) to define the step grain-size distribution.

[21] We classified immobile steps using a combination of our own criteria and the method developed by Zimmermann et al. [2008]. Our criteria were that a step needed to be relatively immobile and therefore should be Boulder or boulder-Cobble patches, which were composed of the largest grain sizes on the bed. Steps also spanned at least half the channel width to eliminate individual boulders or small boulder clusters from being classified as steps. Finally, 
steps had a minimum pool length ( $10 \%$ of bankfull width) and minimum step drop height (3.3\% of bankfull width), as defined by Zimmermann et al. [2008]. Although Zimmermann et al. [2008] included a number of other possible criteria, their step classification was most sensitive to the minimum pool length and drop height and we only use these two measures to simplify step delineation. Our classification resulted in 10 steps (Figure 3a) and the relatively mobile sediment included all of the other patches. We calculated the reach-averaged grain-size distribution as the area-weighted sum of the grain-size distributions of all patches, including steps (Figure $3 b$ ). The grain-size distribution of relatively mobile sediment was the area-weighted sum of all patches excluding steps.

[22] We used our total station survey to calculate a number of other parameters $\left(\mathrm{A}_{\mathrm{m}} / \mathrm{A}_{\mathrm{t}}, \mathrm{D}, \mathrm{p}_{\mathrm{u}}, \lambda_{\mathrm{x}}, \lambda_{\mathrm{w}}, \mathrm{w}\right)$ required to predict sediment flux. The proportion of the bed area occupied by mobile sediment $\left(\mathrm{A}_{\mathrm{m}} / \mathrm{A}_{\mathrm{t}}\right)$ was the total bedparallel area of mobile patches $\left(\mathrm{A}_{\mathrm{m}}\right)$ divided by the total bed area $\left(A_{t}\right)$. The characteristic grain size of the immobile

(a)
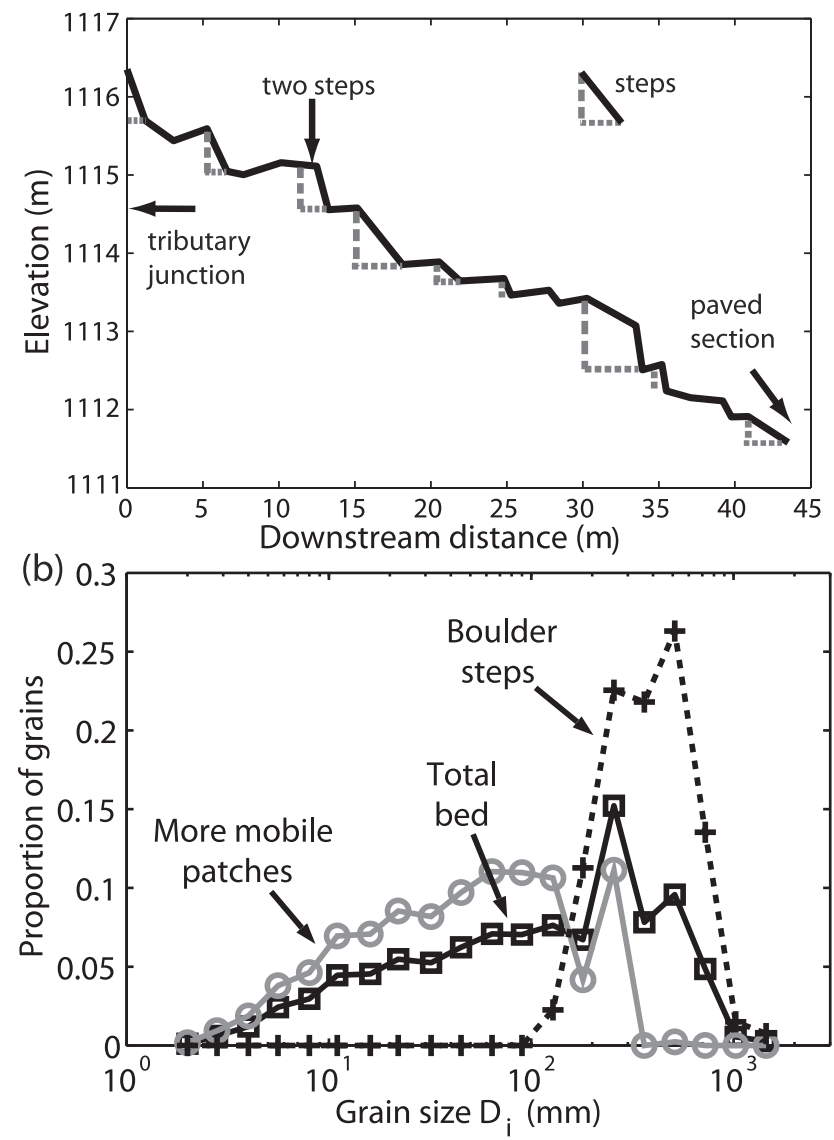

Figure 3. Erlenbach torrent. (a) Immobile-grain steps (dashed gray lines) along the longitudinal profile (solid black line) in the study reach. The upstream and downstream ends of the reach were limited by a tributary junction and fixed cement section, respectively. (b) Grain-size distributions of the relatively mobile sediment, immobile grain steps, and the entire bed (includes immobile-grain steps). grains (D) was the median grain size of the steps. The reach-averaged protrusion $\left(\mathrm{p}_{\mathrm{u}}\right)$ was the average difference between 108 paired elevation measurements of the upstream edges of steps and the neighboring downstream boundaries of mobile patches. The reach-averaged height of the relatively (upstream) mobile sediment $\left(\mathrm{z}_{\mathrm{mu}}\right)$ was D- $\mathrm{p}_{\mathrm{u}}$ (Table 1). The downstream spacing between steps $\left(\lambda_{\mathrm{x}}\right)$ was the total reach length $(40 \mathrm{~m})$ divided by the total number of steps (10). The downstream step length $\left(\lambda_{\mathrm{w}}\right)$ was the total surveyed bed-parallel step area divided by the average channel width and number of steps (Table 1). We used a constant width in our calculations because the confined nature of our study reach did not allow width to significantly vary during sediment transporting flows.

\subsubsection{Flow Measurements and Calibration of Drag Coefficients}

[23] We installed a staff plate in each of three surveyed cross-sections and measured the water surface elevation at each plate throughout seven flow events for a total of 69 measurements in each section. We combined these staff plate data with the corresponding automated measurement (10 min intervals) of flow discharge (uses stage-discharge rating curve) at the downstream end of our reach. For a given flow discharge, the flow depth at each staff plate was an average of maximum and minimum estimates of an unsteady water surface. We developed rating curves between the average flow depth in each cross section and the discharge (see Yager [2006] for details). For each measured discharge, we used these rating curves and surveyed cross sections to calculate the width (W), average flow depth $\left(\mathrm{h}_{\mathrm{a}}\right)$, and flow velocity $(\mathrm{U})$ at each cross section, and for the entire reach. For a given discharge, the reachaveraged flow velocity from this method was similar to that measured using a conductivity probe and dilute saline solution [e.g., Calkins and Dunne, 1970; Day, 1977a, 1977b; Luk and Merz, 1992; Abrahams and Atkinson,

Table 1. Field Measurements Used to Predict Sediment Transport and Flow Conditions ${ }^{\mathrm{a}}$

\begin{tabular}{lccc}
\hline Parameter & Erlenbach & Rio Cordon & Fox Creek \\
\hline Slope (\%) & 9.8 & 17 & 5.0 \\
Width $(\mathrm{m})$ & 4.7 & 5.7 & 5.6 \\
$\mathrm{D}_{50}(\mathrm{~mm})$ & 141 & 129 & 108 \\
$\mathrm{D}_{84}(\mathrm{~mm})$ & 494 & 362 & 221 \\
$\mathrm{D}_{50 \mathrm{~m}}(\mathrm{~mm})$ & 60 & 86 & 19 \\
$\mathrm{D}_{84 \mathrm{~m}}(\mathrm{~mm})$ & 178 & 176 & 88 \\
$\mathrm{~A}_{\mathrm{m}} / \mathrm{A}_{\mathrm{T}}$ & 0.67 & 0.90 & 0.85 \\
$\mathrm{Z}_{\mathrm{mu}}(\mathrm{m})$ & $0.31 \pm 0.01$ & $0.27 / 0.40^{\mathrm{b}}$ & 0.22 \\
$\mathrm{p}_{\mathrm{u}}(\mathrm{m})$ & $0.13 \pm 0.01$ & $0.41 / 0.28^{\mathrm{b}}$ & 0.19 \\
$\mathrm{D}(\mathrm{mm})$ & 442 & 680 & 413 \\
$\lambda_{\mathrm{x}}(\mathrm{m})$ & 4.0 & 6.95 & 5.4 \\
$\lambda_{\mathrm{w}}(\mathrm{m})$ & 1.3 & 0.68 & 0.83 \\
$\mathrm{C}_{\mathrm{m}}$ & $0.44 \pm 0.9$ & $0.44 \pm 0.9$ & $0.44 \pm 0.9$ \\
\hline
\end{tabular}

a“ $\mathrm{m}$ " denotes the relatively mobile sediment. Parameters are the median grain size $\left(D_{50}\right)$, 84th percentile of the grain size distribution $\left(D_{84}\right)$, proportion of the bed covered by mobile sediment $\left(\mathrm{A}_{\mathrm{m}} / \mathrm{A}_{\mathrm{T}}\right)$, depth of the mobile sediment $\left(\mathrm{z}_{\mathrm{mu}}\right)$, and the immobile-grain: protrusion $\left(\mathrm{p}_{\mathrm{u}}\right)$, mean diameter (D), downstream spacing $\left(\lambda_{\mathrm{x}}\right)$, and downstream length $\left(\lambda_{\mathrm{w}}\right)$. Uncertainties in $\mathrm{z}_{\mathrm{mu}}, \mathrm{C}_{\mathrm{m}}$, and $\mathrm{p}_{\mathrm{u}}$ are standard errors.

${ }^{\mathrm{b}}$ Denotes that two different values of protrusion and $z_{\mathrm{mu}}$ in the Rio Cordon were used in all sediment transport equations shown in Table 2 (see text for details). 
1993; Li and Abrahams, 1996; Lee and Ferguson, 2002; Curran and Wohl, 2003; Yager, 2006].

[24] Our stress-partitioning equations require two drag coefficients $\left(\mathrm{C}_{\mathrm{m}}\right.$ and $\left.\mathrm{C}_{\mathrm{I}}\right)$ to predict the reach-averaged flow hydraulics $\left(\mathrm{h}_{\mathrm{a}}, \mathrm{U}, \tau_{\mathrm{m}}\right.$, and $\left.\tau_{\mathrm{t}}\right)$. We calibrated $\mathrm{C}_{\mathrm{m}}$ (0.44) using the measured flow (discharge, velocity, and depth) and bed grain size in a steep stream with relatively few boulders. We then used the measured flow and channel bed conditions (e.g., step spacing, grain size, and protrusion) in the Erlenbach to calibrate $C_{I}$ over a range of flow discharges. Further information on the drag coefficient calibration can be found in the appendix.

\subsubsection{Hiding Function Calibration}

[25] The hiding function (equation (A9)) in the Parker [1990] equations was empirically calibrated to measurements in Oak Creek, a relatively low-gradient stream [Parker, 1990], and can vary significantly between streams or experiments [e.g., Parker et al., 1982; Wilcock and Southard, 1988; Ashworth and Ferguson, 1989; Parker, 1990; Ashworth et al., 1992; Kunle, 1980; Wilcock, 1993; Wathen et al., 1995; Wilcock and Crowe, 2003; Mao et al., 2008]. We therefore calibrated hiding functions in the Erlenbach using tracer particle movements during five flow events. Further details on the hiding function calibration are provided in the appendix.

[26] We assume that we can replace the hiding functions in the original and modified Parker equations with those calibrated in the Erlenbach. We make this assumption because we do not have volumetric grain-size data for the transported sediment in the Erlenbach. If we had such data, we could recalibrate the entire set of Parker equations. We acknowledge that all of the Parker [1990] equations were developed together and to properly modify these equations we should not just alter the hiding function. However, we have performed this calculation to determine if altering the hiding function would be a useful approach. We replaced the hiding function in the original Parker equations with

$$
\phi_{\mathrm{i}}=\omega \phi_{\mathrm{sgo}}\left(\frac{\mathrm{D}_{\mathrm{i}}}{\mathrm{D}_{\mathrm{sg}}}\right)^{-0.377},
$$

and in the modified Parker equations with

$$
\phi_{\mathrm{mi}}=\omega_{\mathrm{m}} \phi_{\mathrm{sgom}}\left(\frac{\mathrm{D}_{\mathrm{i}}}{\mathrm{D}_{\mathrm{sgm}}}\right)^{-0.845} .
$$

The value for the dimensionless reference stress $\left(\tau_{\text {rsgo }}^{*}\right)$ was also calibrated and was replaced with 0.14 and 0.07 for the original and modified Parker equations, respectively. These two hiding functions were obtained using the same tracer particle measurements in the Erlenbach but they were referenced to either the total or mobile grain-size distributions of the bed for the original and modified Parker equations, respectively. A number of different hiding function and sediment transport equation combinations were tested (see section 3.3 for details) and each of these combinations is shown in Table 2.

\subsection{Rio Cordon}

[27] To provide a further test of our combined stresspartitioning and sediment transport equations, we used reach-averaged values for $\mathrm{w}, \mathrm{S}$ (from Lenzi et al. [2004]), $\mathrm{D}$, downstream protrusion, and $\lambda_{\mathrm{x}}$ (from Lenzi [2001]) measured in the Rio Cordon, an instrumented watershed in Italy (Table 1). We also used the flow hydrographs and transported sediment volumes (from Lenzi et al. [1999]), and bed and bed load grain-size distributions (from Mao and Lenzi [2007]) in previously published literature. This is the only steep channel for which we could find publicly available data that allow us to calculate sediment transport rates using our stress partitioning equations. No other published data sets on steep channels contain detailed measurements of the step properties, flow hydrographs, grain-size distribution of the channel bed, and transported sediment volumes; most publications only contain a portion of the necessary data [e.g., Whiting et al., 1999; Lee and Ferguson, 2002; Gomi and Sidle, 2003; Marion and Weirich, 2003; MacFarlane and Wohl, 2003].

[28] The relatively mobile grain size for the Rio Cordon was not measured. To determine this distribution, we first calculated the proportion of the bed covered by the relatively immobile sediment using equation (A16) and the measured step characteristics (Table 1). We then assumed that this same proportion of the total grain-size distribution was only from the immobile steps rather than being part of both the mobile and immobile sediment. We eliminated this percentage of the coarsest grain sizes (which resulted in the removal of grains coarser than $360 \mathrm{~mm}$ ) to obtain the grain-size distribution of the mobile sediment. We also assumed that $\lambda_{\mathrm{w}}$ was equal to one immobile grain diameter (Table 1) because it was not measured. Finally, only the downstream step height was measured in the Rio Cordon, whereas we require the upstream step protrusion to predict the sediment flux. In the Erlenbach, the upstream step protrusion $\left(D-z_{m u}\right)$ can be $28 \%-42 \%$ of the downstream step height, depending on the relative sediment availability [E. M. Yager, unpublished data]. We therefore calculated

\begin{tabular}{|c|c|c|c|c|}
\hline Equation/Hiding Function (hf) & Hiding Function Coefficient & Hiding Function Exponent & Grain Size Distribution & Shear Stress \\
\hline Parker/Parker hf & 0.0386 & -0.9049 & Total & Total \\
\hline Parker/Erlenbach hf (total bed) & 0.14 & -0.62 & Total & Total \\
\hline Modified Parker/Erlenbach hf (mobile) & 0.07 & -0.16 & Mobile & Mobile \\
\hline Parker/Rio Cordon $\mathrm{hf}^{\mathrm{b}}$ & 0.189 & -0.639 & Total & Total \\
\hline Modified Parker/Rio Cordon hf ${ }^{b}$ & 0.189 & -0.639 & Mobile & Mobile \\
\hline
\end{tabular}

Table 2. Matrix of Sediment Transport Equations, Hiding Functions, and Parameters Used in each Bedload Calculation ${ }^{\text {a }}$

\footnotetext{
"Grain size distribution denotes the distribution used to calculate sediment flux where "total" is the entire bed and "mobile" is all patches except the
} immobile steps (see Figure 3b). For shear stress, total (equation (2)) and mobile (equation (3)) are the shear stresses used to calculate bedload transport.

${ }^{\mathrm{b}}$ Denotes that the Rio Cordon hiding function was only used in the Rio Cordon predictions. 
two possible end members for the upstream step protrusion in the Rio Cordon and test these two values in our transport calculations.

\subsection{Prediction of Sediment Flux in the Erlenbach and Rio Cordon}

[29] To predict the sediment fluxes for each event in the Rio Cordon and Erlenbach, we first calculated $h_{a}$ using equation (1), calibrated values for $\mathrm{C}_{\mathrm{I}}$ and $\mathrm{C}_{\mathrm{m}}$ (see the appendix), and the measured flow hydrographs, S, W, D, $\lambda_{\mathrm{x}}$, $\lambda_{\mathrm{w}}$, and $\mathrm{z}_{\mathrm{mu}}$ (Table 1). We then used these flow depths to determine the total shear stresses (equation (2)) and stresses on the mobile sediment (equation (3)) throughout each hydrograph. The stresses on the mobile sediment, the fractional bed area occupied by mobile sediment $\left(\mathrm{A}_{\mathrm{m}} / \mathrm{A}_{\mathrm{t}}\right)$, and the mobile grain sizes were used in the modified Parker equations. The original Parker equation (see the appendix) requires total shear stresses and the grain sizes of the entire bed to predict sediment fluxes.

[30] We made four different predictions of bed load flux for each sediment transport event in the Erlenbach, using different combinations of sediment transport equations and hiding functions (see Table 2). In the original Parker equation, we used either the original (equation (A9)) or Erlenbach-calibrated hiding function for the entire bed (equation (4)). For the modified Parker equation, we used either the original (equation (A9)) or Erlenbach-calibrated hiding function for the mobile sediment (equation (5)). A list of the hiding function exponents and coefficients and the relevant shear stress and grain size distributions for each combination of sediment transport equations and hiding functions is given in Table 2 .

[31] In the Rio Cordon, we used all of the above combinations of equations but also added a Rio Cordon hiding function, which was developed using the total shear stress, tracer particle movements, and the grain-size distribution of the entire bed [Mao and Lenzi, 2007]. Although this hiding function is for the entire bed, we tested it in both the original and modified Parker equations to provide a range of tested hiding function exponents and coefficients. Thus, in each sediment transport equation (original or modified Parker) we used three different possible hiding functions (original Parker, Erlenbach, or Rio Cordon, see Table 2 for values) for a total of six different equation combinations. We used two different values of protrusion in all six of these equation combinations to better understand the impact of our protrusion uncertainty in the Rio Cordon on sediment flux predictions. There were therefore a total of 12 bed load transport predictions for each event in the Rio Cordon.

[32] For each event, the total transported sediment volume was the sum of the predicted fluxes (in $\mathrm{m}^{2} \mathrm{~s}^{-1}$ ) for each measured discharge (above a base flow of $0.1 \mathrm{~m}^{3} \mathrm{~s}^{-1}$, which was far below the threshold for gravel entrainment) multiplied by the measurement duration and channel width. In the Erlenbach (16 events) and Rio Cordon (six events), we assumed channel conditions $\left(\mathrm{S}, \mathrm{W}, \mathrm{D}, \lambda_{\mathrm{x}}, \lambda_{\mathrm{w}}, \mathrm{z}_{\mathrm{mu}}\right.$, and grain-size distributions) did not change between the events.

\subsection{Measurement and Prediction of Flow in Fox Creek}

[33] To independently test our calibrated stress-partitioning equations, we measured the flow hydraulics, grain size, and step characteristics in Fox Creek, a tributary of the Eel River in northern California (Table 1). We made a patch map that included the bed topography, longitudinal profile, step spacing, and protrusion. We also conducted pebble counts on each patch class and divided the bed between immobile steps and relatively mobile sediment. We measured the flow depth using a pressure transducer installed in a cross section and measured the flow velocity using a dilute salt tracer and conductivity probe. We followed the methodology outlined in section 3.1.2 for all of these measurements.

[34] We calculated the measured friction factor (f) using 13 simultaneous measurements of flow velocity and flow depth for flow discharges that ranged from base flow $\left(\sim 0.09 \mathrm{~m}^{3} \mathrm{~s}^{-1}\right)$ to near bankfull $\left(\sim 0.9 \mathrm{~m}^{3} \mathrm{~s}^{-1}\right)$. We predicted $\mathrm{f}$ using our stress partitioning equations with drag coefficients that were calibrated to the Erlenbach. We also used published resistance equations by Lee and Ferguson [2002], Rice et al. [1998], Zimmermann [2010], and Jarrett [1984]. In all of these resistance (except Zimmermann) and our stress partitioning equations, we iteratively solved for the flow depth using the measured discharge, grain size, and step characteristics (when applicable).

\section{Results}

\subsection{Test of Calibrated Stress-partitioning Equations}

[35] We first test our calibrated (to the Erlenbach) stresspartitioning equations and a number of other resistance equations in Fox Creek. The measured friction factor ( $f$ ) declined rapidly as a power function of increasing flow discharge, with relatively small decreases in $\mathrm{f}$ at higher flows (Figure 4). Our stress partitioning equation captured the overall relationship between the friction factor and unit discharge. All other resistance equations did not predict a large change in the friction factor with increasing flow

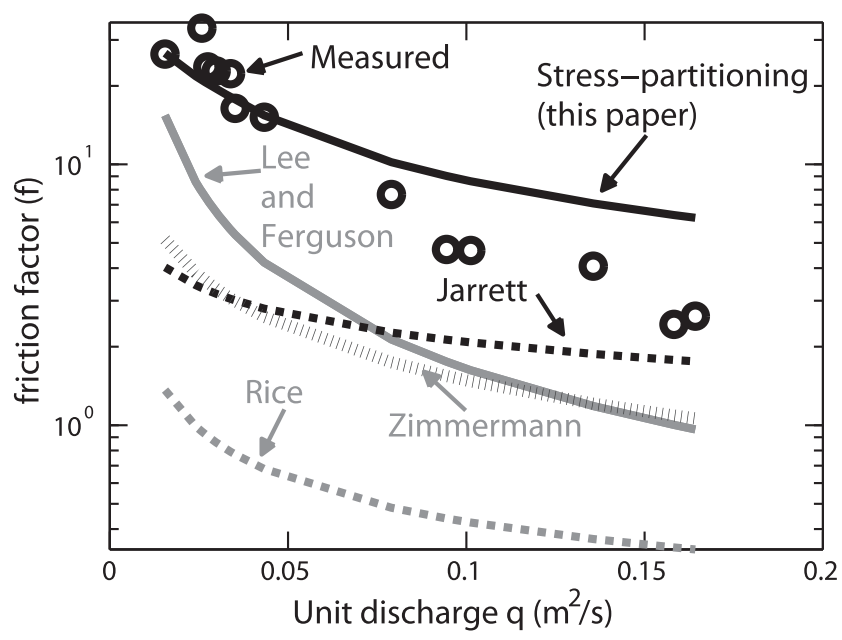

Figure 4. The measured and calculated friction factors in Fox Creek as functions of the unit discharge. Measured (circles) and predicted values from the Lee and Ferguson (solid gray line), Jarrett (dashed black line), Rice (dashed gray line), Zimmermann (dotted gray line), and our calibrated (to the Erlenbach) stress partitioning (solid black line) equations are shown. 
discharge, and systematically underpredicted the friction factor. Our stress partitioning equation had a root-meansquare error (RMSE) in predicted $f$ of 11 , which was the lowest value of all tested resistance equations. The equation of Jarrett had the next lowest RMSE of 18 and all other equations had a RMSE greater than 20. This independent test of our stress-partitioning equations suggests that they can predict flow hydraulics fairly accurately and may be used to calculate sediment flux.

\subsection{Prediction of Sediment Flux in the Erlenbach}

[36] The original Parker equation, with the original hiding function, overpredicted the measured sediment volumes by several orders of magnitude for $47 \%$ of the measurements (Figure 5) and was within an order of magnitude $53 \%$ of the time (Table 3). Our modified Parker equation, with the original hiding function, underpredicted the sediment volumes by several orders of magnitude for $20 \%$ of the measurements and was within an order of magnitude of the measured values for $80 \%$ of the data (Figure 5 ). We now determine if the modified and original Parker equations perform better with the calibrated hiding functions

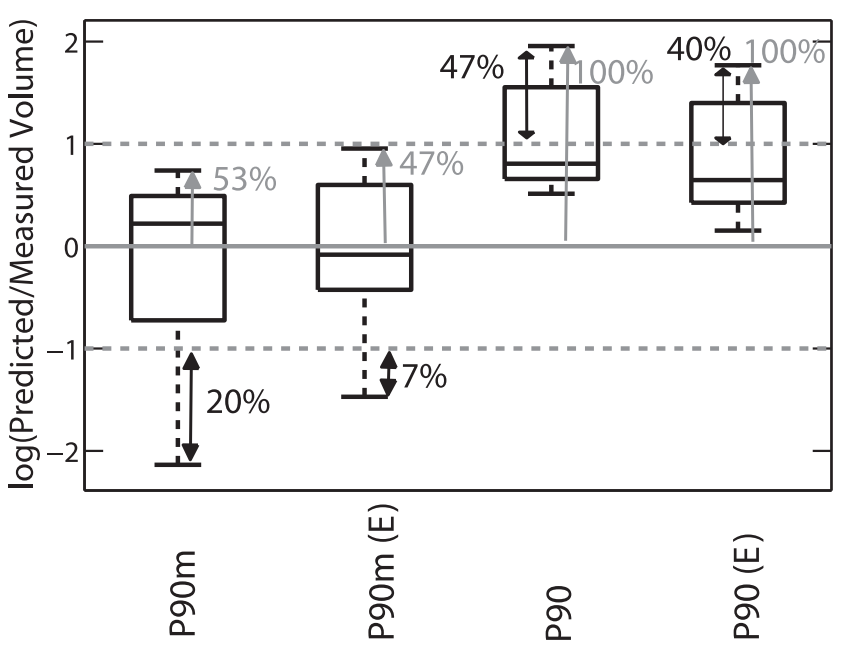

Figure 5. The log of the ratio of the predicted to measured sediment volumes in the Erlenbach. The original Parker equation with the original (P90) and Erlenbach (P90 E) hiding functions and the modified Parker equation with original (P90m) and Erlenbach (P90m E) hiding functions are shown. Negative and positive sediment volume ratios represent sediment predictions that are greater or less than, respectively, the measured values. The top and bottom of each box represent the 25 th and 75 th percentiles of the data points, respectively, and the line in the middle of each box is the median, which demonstrates skewness of the data if it is not centered in the box. The lines extending out of each box denote the furthest limit of the data points. The gray arrow and the corresponding text denote the percent of the sediment volume predictions that are greater than the measured values. Black arrows and the corresponding text show the percent of the sediment volume predictions that are not within an order of magnitude of the measured values. The solid and dashed horizontal lines represent predicted values equal to or within an order of magnitude of the measured volumes, respectively.
Table 3. Prediction Errors for Sediment Flux Calculations in the Erlenbach $^{\mathrm{a}}$

\begin{tabular}{lcccc}
\hline & P90 & P90 (E) & P90m & P90m (E) \\
\hline RMSE $\left(\mathrm{m}^{3}\right)$ & 397 & 215 & 56 & 34 \\
Within an order of magnitude (\%) & 53 & 60 & 80 & 93 \\
Greater than (\%) & 100 & 100 & 53 & 47 \\
Greater than an order of magnitude (\%) & 47 & 40 & 0 & 0 \\
Less than an order of magnitude (\%) & 0 & 0 & 20 & 7 \\
Within a factor of 2 (\%) & 0 & 7 & 13 & 27 \\
\hline
\end{tabular}

a"Within an order of magnitude" denotes the percent of the predicted sediment fluxes that were within an order of magnitude of the measured values. "Greater than" denotes the percent of the predictions that were greater than the measured values. P90 and P90 (E) are the original Parker equation with the original and Erlenbach (for the total sediment) hiding functions, respectively. $\mathrm{P} 90 \mathrm{~m}$ and $\mathrm{P} 90 \mathrm{~m}(\mathrm{E})$ are the modified Parker equation with the original and Erlenbach (for the mobile sediment) hiding functions, respectively.

(equations (5) and (4), respectively) for the Erlenbach. The original Parker equation, combined with equation (4), overpredicted the sediment volumes by several orders of magnitude for $40 \%$ of the data points (Figure 5, Table 3). The modified Parker equation, combined with equation (5), predicted the sediment fluxes to within an order of magnitude of the measured values for $93 \%$ of the measurements (Figure 5, Table 3).

[37] Calibration of hiding functions to the Erlenbach increased the accuracy of both the original and modified Parker equations. Regardless of the hiding function, the original Parker equation systematically overpredicted sediment volumes whereas the modified Parker equation overpredicted for $\sim 50 \%$ of the data points and therefore straddled the measured values. Of all tested sediment transport and hiding function equations, the modified Parker equation, with the mobile-bed Erlenbach hiding function, had the lowest root-mean-square error (RMSE).

\subsection{Prediction of Sediment Transport in the Rio Cordon}

[38] The original Parker equation, with the original hiding function, overpredicted the measured sediment volumes by several orders of magnitude for $100 \%$ of the measurements in the Rio Cordon (Figure 6a, Table 4). In general, use of either the total-bed Erlenbach or Rio Cordon hiding functions reduced the RMSE of the predicted sediment volumes. Calculations using these hiding functions still caused the original Parker equation to overpredict the measured sediment volume by several orders of magnitude for $83 \%$ of the data points (Table 4, Figure 6a). Use of different values for protrusion in the original Parker equation, regardless of hiding function, did not significantly alter the performance of this equation.

[39] The modified Parker equation, with the original hiding function and a high protrusion, underpredicted the sediment volumes by several orders of magnitude for $17 \%$ of the measurements and was within an order of magnitude of the measured values for $67 \%$ of the data (Figure $6 \mathrm{~b}$ ). Use of the Rio Cordon and mobile-bed Erlenbach hiding functions did not significantly alter the RMSE of the modified Parker equation (Table 4). However, the modified Parker equation, combined with the Rio Cordon hiding function, increased the percent of predicted data points that were 
(a)

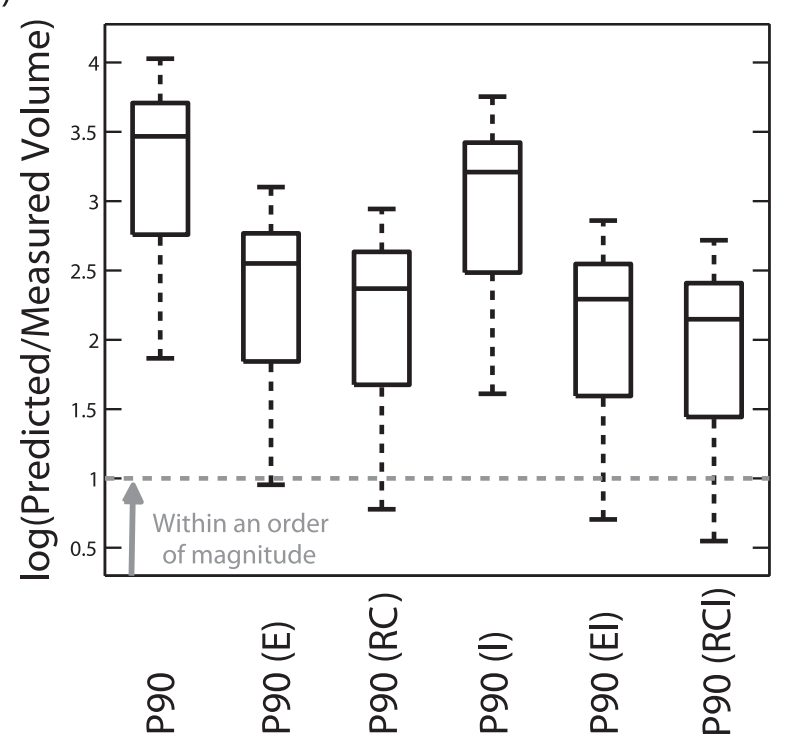

(b)

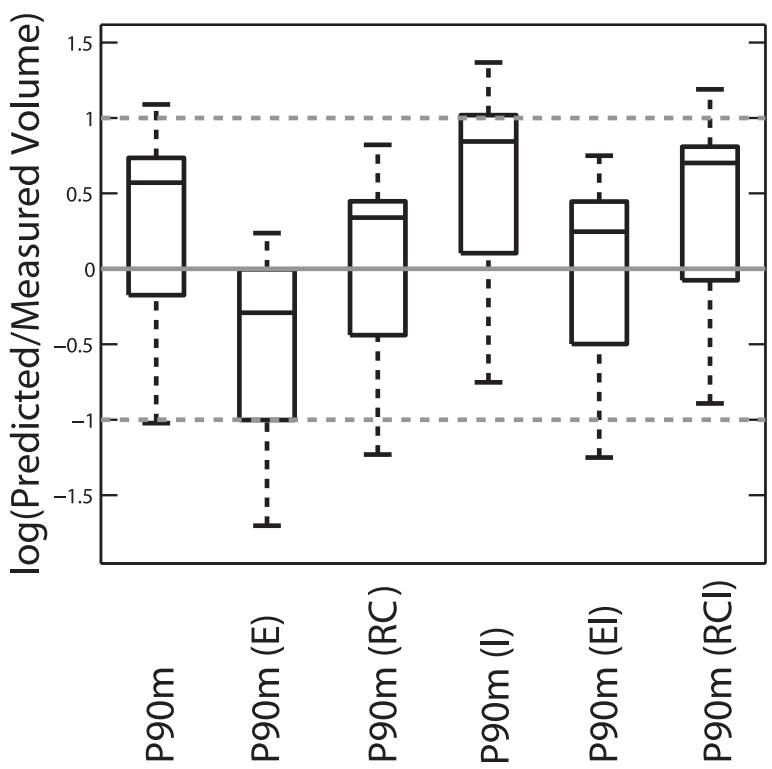

Figure 6. The $\log$ of the ratio of the predicted to measured sediment volumes in the Rio Cordon. (a) Predictions using the original Parker equation with high and low protrusions and the original (P90), Erlenbach (P90 E), and Rio Cordon (P90 RC) hiding functions. (b) Predictions using the modified Parker equation with high and low protrusions and the original (P90m), Erlenbach (P90m E), and Rio Cordon (P90m RC) hiding functions. I denotes low protrusion, all other equations used a high protrusion. The solid and dashed horizontal lines represent predicted values equal to or within an order of magnitude of the measured volumes, respectively. See Figure 5 for an explanation of the box properties.

within an order of magnitude of the measured values to $83 \%$ (Figure 6 b, Table 4 ).

[40] The modified Parker equation was relatively sensitive to changes in the upstream step protrusion, depending on the hiding function. Use of a low protrusion with the original hiding function increased the RMSE and caused a large systematic overprediction of the sediment flux. The RMSE of the predictions using the mobile-bed Erlenbach or Rio Cordon hiding functions did not vary significantly with protrusion. However, more data points were systematically under- or over-predicted when a high or low protrusion, respectively, was used with the mobile-bed Erlenbach hiding function (Figure 6b, Table 4). When a low protrusion was used with the Erlenbach hiding function, transport predictions had similar accuracy to those using the modified Parker equation with the Rio Cordon hiding function. It is likely that the mobile-bed Erlenbach hiding function with a moderate value of protrusion would yield the optimal combination of predictions straddling, and being to within an order of magnitude, of the measured values. Thus, both the choice of protrusion and hiding function can significantly impact sediment volume predictions from the modified Parker equation.

[41] Of all combinations of sediment transport equations and hiding functions, the modified Parker equation, with either the Rio Cordon (high or low protrusion) or mobile-bed Erlenbach (low protrusion) hiding functions, had the largest percentage of predictions within an order of magnitude of the measured values (Table 4). Any version of the modified Parker equation had significantly lower RMSE than any version of the original Parker equation (see Table 4).

\subsection{Comparison of Predicted and Measured Transported Grain Sizes}

[42] Five of the previously tested sediment transport events in the Rio Cordon have measured transported grain sizes, which we compare to the predicted grain-size distributions for each event. The measured bed load grain-size distribution progressively coarsened with increasing event magnitude (Figure 7). For small magnitude sediment transport events, the original Parker equation, when combined with either the total-bed Erlenbach or Rio Cordon hiding functions, predicted the transported grain sizes relatively well (Figures $7 \mathrm{a}$ and $7 \mathrm{~b}$ ). Conversely, the transported grain sizes during moderate to large events were predicted with better accuracy using the modified Parker equation, combined with either the original or Rio Cordon hiding functions (Figures 7c-7e). The original Parker equation, when combined with the original hiding function, did not accurately predict the transported grain sizes for any event.

[43] With the exception of the event on 3 July 1989 (Figure 7c), the modified Parker equation, combined with the mobile-bed Erlenbach hiding function, predicted the transported grain sizes fairly accurately. This was the only combination of sediment transport-hiding function equations that mimicked the trend of coarser transported grain sizes with higher event magnitudes. Most other equations over-predicted the transported grain sizes during small magnitude events and underpredicted the sediment sizes during large events (Figure 7). Furthermore, most of the tested equations systematically over-predicted the $\mathrm{D}_{16}$ and underpredicted the $\mathrm{D}_{84}$ (Table 5). The original Parker equation, combined with the total-bed Erlenbach or Rio Cordon hiding functions, and the modified Parker equation, combined with the mobile-bed Erlenbach hiding function, had the lowest RMSE for all tested grain sizes (Table 5). 
Table 4. Prediction Errors for Sediment Flux Calculations in the Rio Cordon ${ }^{\mathrm{a}}$

\begin{tabular}{lcccccc}
\hline & $\mathrm{P} 90$ & $\mathrm{P} 90(\mathrm{E})$ & $\mathrm{P} 90(\mathrm{RC})$ & $\mathrm{P} 90 \mathrm{~m}$ & $\mathrm{P} 90 \mathrm{~m}(\mathrm{E})$ & $\mathrm{P} 90 \mathrm{~m}(\mathrm{RC})$ \\
\hline RMSE $\left(\mathrm{m}^{3}\right)$ & $1.5 \times 10^{5} / 8.3 \times 10^{4}$ & $1.8 \times 10^{4} / 1.0 \times 10^{4}$ & $1.2 \times 10^{4} / 7.2 \times 10^{3}$ & $358 / 405$ & $377 / 361$ & $359 / 367$ \\
Within an order of magnitude (\%) & $0 / 0$ & $17 / 17$ & $17 / 17$ & $67 / 67$ & $67 / 83$ & $83 / 83$ \\
Greater than (\%) & $100 / 100$ & $100 / 100$ & $100 / 100$ & $67 / 83$ & $17 / 67$ & $67 / 67$ \\
Greater than an order of magnitude (\%) & $100 / 100$ & $83 / 83$ & $83 / 83$ & $17 / 33$ & $0 / 0$ & $0 / 17$ \\
Less than an order of magnitude (\%) & $0 / 0$ & $0 / 0$ & $0 / 0$ & $17 / 0$ & $33 / 17$ & $17 / 0$ \\
Within a factor of 2 (\%) & $0 / 0$ & $0 / 0$ & $0 / 0$ & $17 / 17$ & $67 / 67$ & $17 / 17$ \\
\hline
\end{tabular}

a"Within an order of magnitude" denotes the percent of the predicted sediment fluxes that were within an order of magnitude of the measured values. "Greater than" denotes the percent of the predictions that were greater than the measured values. P90, P90 (RC) and P90 (E) are the original Parker equation with the original, Rio Cordon and Erlenbach (for the total sediment) hiding functions, respectively. P90m, P90m (RC) and P90m (E) are the modified Parker equation with the original, Rio Cordon and Erlenbach (for the mobile sediment) hiding functions, respectively. Two values are shown for each equation, separated by a backslash; the first and second values are calculations using a high or low protrusion, respectively.

\section{Discussion}

\subsection{Use of Stress-Partitioning Equations in Three Steep Streams}

[44] Unlike the original Parker equation, the modified Parker equation predicted sediment volumes in the Erlenbach that: had a relatively low RMSE, straddled the measured values, and were within an order of magnitude of the measured values for most of the data. This statement is true for most combinations of hiding functions and sediment transport equations (i.e., original or modified Parker equations). We stress that the modified Parker equation was not calibrated to the transported sediment volumes in the Erlenbach. Only the Erlenbach hiding function was calibrated to tracer particle movements, and the drag coefficient for the immobile sediment $\left(C_{I}\right)$ was calibrated to yield the measured flow conditions in the Erlenbach. Although $C_{I}$ was calibrated to the Erlenbach, our stress partitioning equations performed better in Fox Creek than all of the other tested resistance equations. Furthermore, the modified Parker equation significantly improved predictions of sediment flux in the Rio Cordon without any local calibration. In this stream, the modified Parker equation had a much lower RMSE, and a greater percentage of predictions within an order of magnitude of the measured values, than the original Parker equation (for all hiding function combinations). The modified Parker equation accounts for the effects of relatively immobile grains, limited sediment availability, and size-selective transport. Other sediment transport equations that account for these three effects may also predict the sediment flux in the Erlenbach and Rio Cordon fairly accurately.

\subsection{Hiding Functions for Steep Streams}

[45] We tested hiding functions with a wide range of dimensionless reference shear stresses $(0.0386$ to 0.189$)$ and exponents $(-0.16$ to -0.9049 ; Table 2). In the Rio Cordon, the modified Parker equation, combined with the mobile-bed Erlenbach hiding function, generally predicted sediment fluxes and transported grain sizes with the most accuracy (Figures 6 and 7, Tables 4 and 5). It was only this combination of equations that predicted the observed increase in transported grain sizes with event magnitude. In the Erlenbach, the combination of the modified Parker equation and the mobile-bed Erlenbach hiding function also predicted sediment fluxes better than all of the other tested equation combinations. This hiding function is different from those reported for both low-gradient and steep channels. The small exponent $(-0.16)$ implies that the relatively mobile sediment engages in highly selective transport and that hiding effects are relatively unimportant. Thus, we removed many of the hiding effects (e.g., large grains shelter small grains) by directly accounting for the effects of the large grains on the stress borne by the mobile sediment.

[46] The Rio Cordon hiding function also predicted the transported sediment volumes in the Rio Cordon relatively well, when combined with the modified Parker equation. It did not predict the transported grain sizes as accurately as the mobile-bed Erlenbach hiding function, although it was calibrated to tracer particle movements in the Rio Cordon. Unlike the mobile-bed Erlenbach hiding function, the Rio Cordon hiding function predicted very little change in the transported grain size distributions between events. This is likely because the Rio Cordon hiding function has a higher exponent that does not predict highly size-selective transport. The Rio Cordon hiding function was also calibrated for the entire bed rather than the mobile sediment.

[47] The critical Shields stress in the Erlenbach hiding function $\left(\tau_{\text {rsgo }}^{*}=0.07\right)$ is within the upper range of values reported for lower-gradient streams [e.g., Buffington and Montgomery, 1997]. $\tau_{\text {rsgo }}^{*}$ generally increases with lower relative submergences and higher channel slopes [e.g., Ashida and Bayazit, 1973; Aguirre-Pe, 1975; Graf and Suszka, 1987; Aguirre-Pe and Fuentes, 1991; Bartnick, 1991; Shvidchenko and Pender, 2000; Shvidchenko et al., 2001; Mueller et al., 2005; Lenzi et al., 2006; Lamb et al., 2008; Mao et al., 2008]. The dimensionless critical stress is often higher in steep streams than in lower-gradient channels because roughness elements bear a significant fraction of the total stress [e.g., Buffington and Montgomery, 1997] and/or low relative flow depths reduce the nearbed turbulence intensities [e.g., Lamb et al., 2008]. However, the critical Shields stress is often calculated using reach-averaged flow conditions and not the local forces and turbulence parameters that cause transport. An actual increase in the critical Shields stress in steep channels would occur if the fundamental local forces that initiate motion have changed. Our results imply that corrections for the effects of immobile grains may partially reduce the values of $\tau_{\text {rsgo }}^{*}$ in steep streams to those in channels with relatively low roughness. However, the parameters that control the actual critical Shields stress (e.g., friction angles, protrusion, or grain interlocking) may also be different between steep and lower-gradient channels. 
(a)

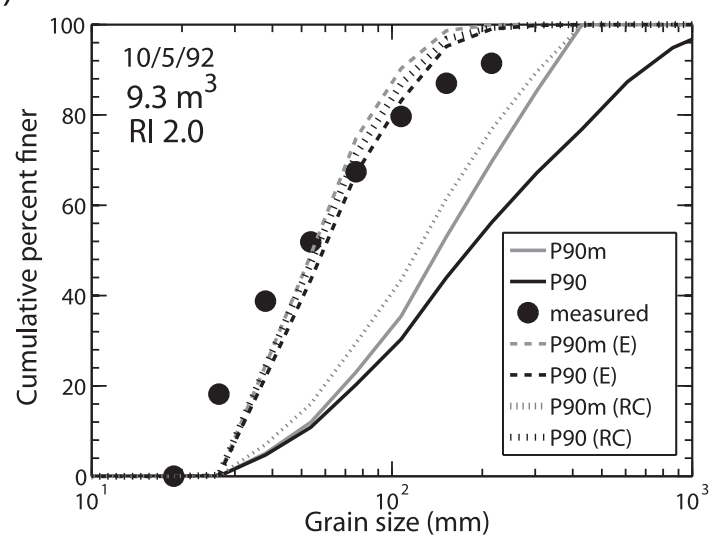

(c)

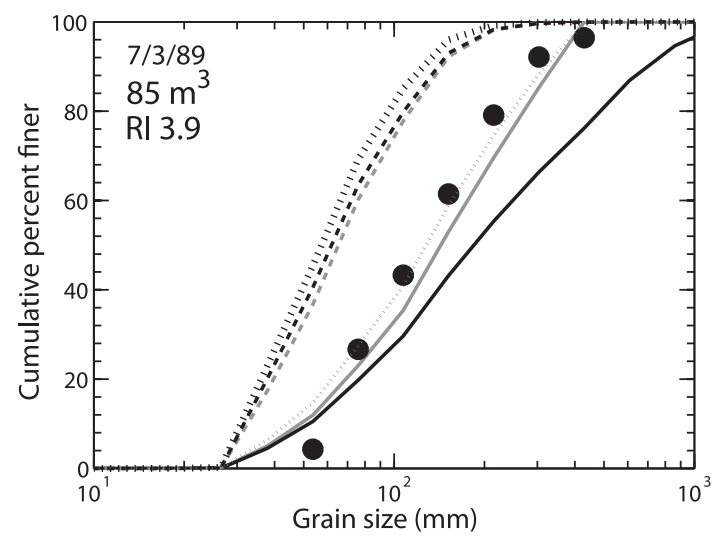

(b)

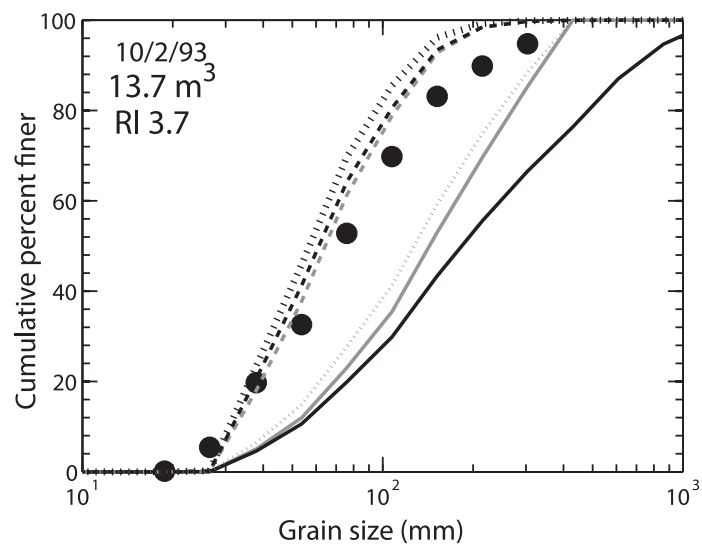

(d)

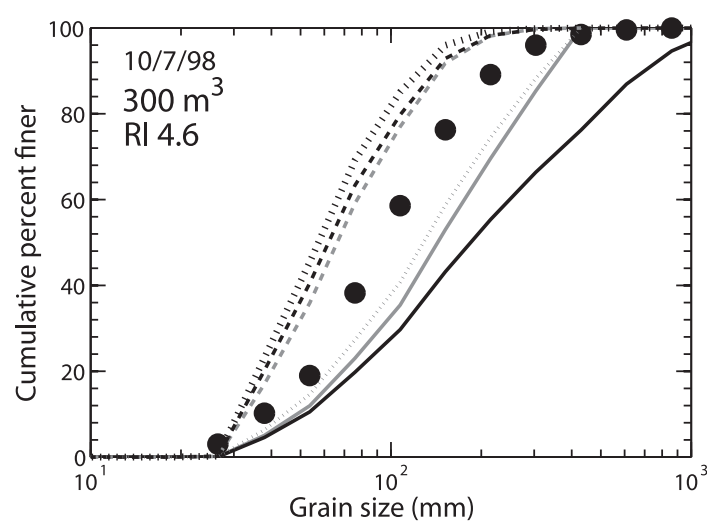

(e)

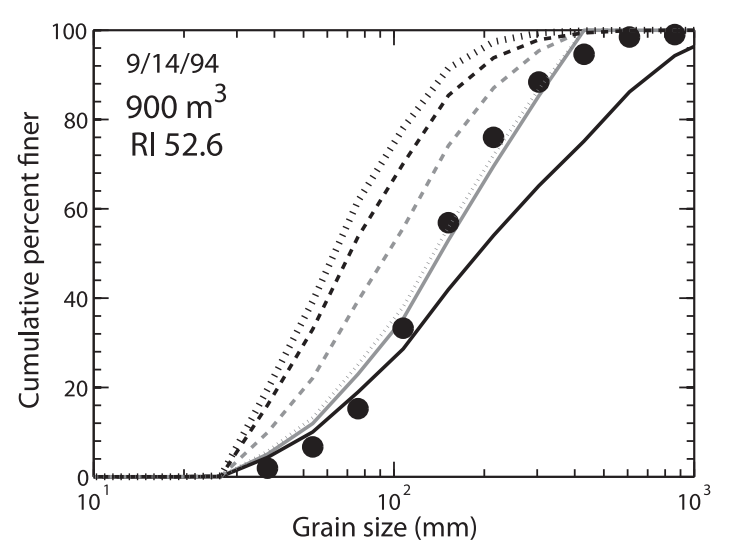

Figure 7. Measured and predicted grain size-distributions in the Rio Cordon that were transported on (a) 5 October 1992, (b) 2 October 1993, (c) 3 July 1989, (d) 7 October 1998, and (e) 14 September 1994. The values below each date represent the total measured transported sediment volume for each event. RI is the recurrence interval [from Lenzi et al., 2004]. See Figure 6 for an explanation of the abbreviations for each sediment transport equation.

[48] Use of hiding functions, calibrated to the entire bed of steep streams (total-bed Erlenbach and Rio Cordon) in the original Parker equation did not significantly improve sediment flux calculations in the Erlenbach and Rio Cordon (Figures 5 and 6; Tables 3 and 4). These hiding functions use dimensionless reference shear stresses within the range of values reported for steep streams (Table 2). We also tested if simply changing $\tau_{\text {rsgo }}^{*}$ in the original Parker equation could improve sediment flux predictions without the use of stress partitioning. In the Rio Cordon, to obtain comparable RMSE in predicted sediment volumes to those from the modified Parker equation, $\tau_{\text {rsgo }}^{*}$ must be equal to $\sim 0.4$. Use of this $\tau_{\text {rsgo }}^{*}$ still caused the original Parker equation to systematically over-estimate sediment flux for $67 \%$ of the data points. Furthermore, 0.4 is generally larger than the reported empirical and theoretical range of $\tau_{\text {rsgo }}^{*}$ for steep channels (see Lamb et al. [2009] for a review). In the Erlenbach, use of this value for $\tau_{\text {rsgo }}^{*}$ in the original Parker 
Table 5. RMSE (mm) of the Predicted Transported Grain Sizes in the Rio Cordon ${ }^{\mathrm{a}}$

\begin{tabular}{lccc}
\hline \multicolumn{1}{c}{ Equation } & RMSE D $_{84}$ & RMSE D $_{50}$ & RMSE D $_{16}$ \\
\hline P90 & 427 & 124 & 34 \\
P90 (E) & 21 & 12 & 7 \\
P90 (RC) & 32 & 14 & 7 \\
P90m & 163 & 82 & 29 \\
P90m (E) & 26 & 12 & 6 \\
P90m (E. low p) & 37 & 21 & 10 \\
P90m (RC) & 142 & 67 & 23 \\
\hline
\end{tabular}

${ }^{\mathrm{a}}$ See Table 4 for an explanation of abbreviations. "Low p" denotes low protrusion, all other values use a high protrusion (see Table 1).

equation caused the measured sediment volumes to be under-predicted by many orders of magnitude for all data points. Thus, simply increasing the value of $\tau_{\text {rsgo }}^{*}$ in steep channels may not result in critical shear stress values that are transferable between streams or better predictions of sediment flux.

\subsection{Prediction and Measurement Uncertainties}

[49] Although our modifications significantly improved bed load predictions, the predicted fluxes were only to within a factor of 2 of the measured fluxes for $27 \%$ (Table 3) and $67 \%$ (Table 4 ) of the data points in the Erlenbach and Rio Cordon, respectively. These predictions are still significant improvements over those from the original Parker equation, which were only within a factor of 2 for $0 \%-7 \%$ of the data points (see Tables 3 and 4 ). The persistence of errors in our modified equations suggests that future work is needed to better understand and improve predictions of transport processes in steep channels. The discrepancies between the measured and predicted sediment volumes in the Erlenbach could be caused by assumptions in the stress-partitioning and modified Parker equations. For all events, we assumed the grain-size distribution of the relatively mobile sediment and the immobile-grain spacing, size, and protrusion were constant. During this time period, no event was large enough to move the immobile-grain steps and change their downstream spacing. Furthermore, the yearly sediment yield remained relatively constant and therefore the sediment availability and the parameters that depend on it (grain size, area occupied by mobile sediment, and step protrusion) may not have significantly changed. However, the sediment supply for any given event, which controls the grain size of the relatively mobile sediment and the immobile-grain protrusion $\left(\mathrm{p}_{\mathrm{u}}\right)$ and downstream length $\left(\lambda_{\mathrm{w}}\right)$, could have varied. A theory is still needed to predict the variation of $p_{u}$ and the mobile grain sizes with sediment supply and shear stress. Without such a theory, we cannot determine how these parameters will change between and within sediment transport events.

[50] We also assumed the bed characteristics did not change in the Rio Cordon because no data were available on the event-scale variations of these parameters. Some of our tested events in the Rio Cordon transported large boulders, and likely altered the sediment availability and step characteristics. Thus, some of the errors in the Rio Cordon are very likely caused by the use of static bed conditions. Our assumed values for the downstream step length, mobile grain-size distributions, and step protrusion may have also introduced prediction errors.
[51] Prediction errors may have also occurred from assuming constant drag coefficients for all streams (Rio Cordon, Erlenbach, and Fox Creek); it is likely that the drag coefficient for the immobile steps may vary with the step spacing. In addition, the modified Parker equation does not account for the spatial variability in grain size and critical and applied shear stresses. All of these parameters vary significantly in steep streams [Yager, 2006], and neglecting this variation can cause large errors in the predicted sediment flux [Ferguson, 2003]. In particular, patches are composed of relatively narrow grain-size distributions that move under local flow conditions that are distinct from reach-averaged values [e.g., Dietrich et al., 2005; Nelson et al., 2009; Yager, 2006]. Patch sorting and channel location (high- versus low-stress environments) influence the relatively mobility of a given grain size [Yager, 2006]. Thus, errors in our sediment volume and grain size predictions may be partially caused by using the reach-averaged Parker equation in a patchy stream. We did not know the local stress conditions over each patch and therefore could not predict the sediment flux on individual patch classes. We have developed a set of flow and transport equations that only require the flow discharge and reach-averaged bed properties. If more detailed flow information is known, equations such as those developed by Kean and Smith [2006a, 2006b] and Kean et al. [2009] could be modified to predict the spatial variability in shear stress for rough streams.

[52] Finally, the measured sediment volumes in the Erlenbach and Rio Cordon have associated uncertainties that may cause some of the differences between the predicted and measured values. For example, the bed load sensors in the Erlenbach only measure grains coarser than $1 \mathrm{~cm}$. The proportion of the sediment volume in the retention basin represented by this size is assumed to be constant in the bed load sensor calibration. It is unlikely that this proportion actually remains constant with event magnitude and therefore the bed load sensors may under- or overestimate the bed load flux of grains coarser than $1 \mathrm{~cm}$, depending on the flow discharge. Although this could impact our prediction errors, we do not see any systematic differences between the measured and predicted fluxes with event magnitude. The uncertainties in such measurements are discussed in detail in the original data sources for these measurements [e.g., Rickenmann and McArdell, 2007; Lenzi et al., 1999].

\subsection{Application to Other Steep Streams}

[53] The Rio Cordon, Erlenbach, and Fox Creek represent a wide range of bed coverage by mobile sediment, step spacing and protrusion, channel slope, and immobile and mobile grain sizes (Table 1). Thus, our combined stresspartitioning and sediment transport equations have the potential to improve predictions of flow, velocity, shear stress, and sediment flux in other steep channels without individual stream calibration. A slightly different set of these equations that were developed for cascade channels, also predicted sediment flux and flow hydraulics better than all of the other tested resistance and sediment transport equations, when compared to flume data. These experiments used a wide range in the upstream sediment supply, boulder spacing, and protrusion [Yager et al., 2007]. 
[54] The tested events in the Erlenbach had recurrence intervals that ranged from $<0.1$ to $\sim 1.5$ and in the Rio Cordon from 2 to 52.6 [Lenzi et al., 2004]. Our modified equations are capable of predicting sediment fluxes for small, frequent, and large channel-changing events. We do not recommend, however, using our equations in events that move the steps because the modified Parker equation is based on the assumption that steps are immobile. These large boulders move during relatively infrequent, large magnitude events [e.g., Lenzi, 2001; Turowski et al., 2009]. Relatively little is known about the mechanics of step formation and disintegration, and such research is beyond the scope of our study. We recommend that future work focus on determination of the forces and bed and flow conditions that are responsible for step disintegration. Until the mechanics of boulder movement are better understood, we recommend determining the appropriate sediment transport equation based on the recurrence interval of a given flow or empirical/theoretical estimates of boulder mobility [e.g., Lamb et al., 2008, Recking, 2009; Turowski et al., 2009]. Sediment transport equations developed for lower-gradient channels, which do not partition the total shear stress and allow for boulder movement, work relatively well during large events in which all grain sizes are mobile [e.g., Bathurst et al., 1987; Rickenmann, 1997; D'Agostino and Lenzi, 1999]. Thus, the modified Parker equation would be applicable up to a certain flow condition, above which the original Parker or similar equation should be used. This exact threshold between applicable bed load equations will depend on the relative mobility of the boulder steps in a given channel. The modified and original Parker equations will predict the same bed load flux when the mobile and total grain size distributions are equivalent and the step protrusion is zero.

[55] The set of equations outlined here are only for steppool channels and are not directly applicable to cascade streams. However, the stress-partitioning equations developed by Yager et al. [2007] are for cascade morphologies and when combined with the modified Parker equation could be used to predict sediment flux in such streams. The modified Parker equation presented here was derived for steep channels with boulder steps. It could be altered to account for sediment transport over wood-dominated steps by substituting the boulder parameters $\left(\mathrm{D}, \mathrm{p}_{\mathrm{u}}, \lambda_{\mathrm{x}}, \lambda_{\mathrm{y}}, \lambda_{\mathrm{w}}\right)$ with those relevant for woody debris (e.g., spacing between wood steps, upstream protrusion of wood, wood diameter).

[56] The majority of published bed load transport equations have limited testing in only one or a few field locations, which preclude their wide applicability. Therefore, we recommend future collection of bed load transport data to test both the modified Parker and other bed load transport equations for a wider variety of upstream sediment supplies, step spacing, and protrusion values. A recent study also demonstrates that our stress-partitioning approach predicts bed load flux and flow conditions relatively accurately in a range of steep streams, especially those with high-boulder concentrations [Nitsche et al., 2011]. Furthermore, although our Erlenbach hiding function, when combined with the modified Parker equation, predicted sediment flux relatively accurately in two streams, it also requires further testing in other steep channels to determine its general applicability. Given the wide range in published hiding functions for lower-gradient channels, we expect some variability in the hiding function between steep channels. General application of the modified Parker equation will be improved if $C_{I}$ and $C_{m}$ are calibrated using reach-averaged flow measurements in a range of other streams. Detailed laboratory experiments of the flow and pressure fields around grains [e.g., Kalinske, 1943; Nelson et al., 1995; Papanicolaou et al., 2001; Kean and Smith, 2006a; Schmeeckle et al., 2007] could also provide data to calibrate these drag coefficients. The field approach continues our treatment of $C_{I}$ and $C_{m}$ as bulk roughness coefficients, whereas detailed laboratory measurements determine the actual drag coefficients.

[57] The modified Parker equation requires relatively few additional measurements $\left(\mathrm{p}_{\mathrm{u}}, \lambda_{\mathrm{w}}, \lambda_{\mathrm{x}}\right)$ to those used in the original Parker equation (S, q, grain-size distribution). Our detailed topographic measurements of the immobilestep protrusion, spacing, and downstream length are not required; these would only require tape measurements. A number of pebble counts are needed to characterize the grain sizes of the mobile and immobile sediment. For more detailed flow calculations, the step protrusion, cross-stream packing, and down-stream spacing may be estimated for regular and irregular step arrangements following the methodology of Kean and Smith [2006a, 2006b]. In Appendix 4, we have outlined the measurements and calculations necessary to apply the modified Parker equation to other steep streams.

[58] Bed load transport equations are often applied to determine the sediment flux and channel conditions (e.g., width, slope, grain size) throughout watersheds. Such calculations are used for different river restoration scenarios and to evaluate the impact of land-use practices on downstream river conditions and aquatic habitat. Predictions of sediment routing through watersheds currently use sediment transport equations developed for lower-gradient channels, which significantly over-predict the sediment flux out of steep steams. Steep streams are the majority of the total channel length in mountainous drainage networks and are the direct link between hillslope processes and lower-gradient channels. Thus, over-predicted sediment fluxes may influence the predicted channel slopes (may increase to transport the high sediment load) and grain sizes (may decrease with high supply) throughout watersheds. With additional field verification, the modified Parker or similar bed load equations could improve basin-scale slope and grain size predictions. Such basin-scale sediment flux predictions require less-detailed bed measurements than we have outlined here. Field measurements in a number of steep streams could determine possible ranges in the grainsize distribution of the relatively mobile sediment and the immobile-step protrusion and spacing. In theory, an equation that predicts these parameters from the upstream sediment supply (obtained from hillslope erosion models) could be also combined with the modified Parker equation.

\section{Conclusions}

[59] We previously developed a combined set of modified sediment transport and stress-partitioning equations for cascade channels but only tested these equations using flume experiments with a single mobile grain size. Here, 
we further modify these equations to include the effects of immobile grain steps and selective transport (using the Parker [1990] bed load equations) of the relatively mobile sediment. This set of equations significantly improved sediment flux and flow predictions in a number of steep channels. Unlike the other transport equations that we tested, this modified Parker [1990] equation mostly predicted the sediment volumes to within an order of magnitude of the measured values and had the lowest RMSE. The modified Parker [1990] equation obtained the most accurate sediment flux and transported grain size predictions when it was combined with a hiding function that calculates highly selective transport of the relatively mobile sediment. Use of a large critical Shields stress, such as those reported in steep streams, does not systematically improve bed load transport calculations in all tested streams. The modified Parker equation performs well because it accounts for the stress borne by the relatively immobile grains, and the limited availability and size-selective transport of the more mobile sediment.

\section{Appendix A}

\section{Appendix A1 : Calibration of Drag Coefficients}

[60] $\mathrm{C}_{\mathrm{I}}$ may vary with the immobile-grain spacing $\left(\lambda_{\mathrm{x}}\right.$ and $\left.\lambda_{\mathrm{y}}\right)$ and relative submergence $\left(\mathrm{h}_{\mathrm{a}} / \mathrm{p}_{\mathrm{u}}\right)$ [e.g., Flammer et al., 1970; Nepf, 1999; Wallerstein et al., 2002], whereas $\mathrm{C}_{\mathrm{m}}$ may only vary with the relative submergence of the mobile sediment $\left(\mathrm{h}_{\mathrm{a}} / \mathrm{D}_{\mathrm{m} 84}\right)$. In a given reach, $\lambda_{\mathrm{x}}$ and $\lambda_{\mathrm{y}}$ will remain constant if the immobile steps are stable and the WSL has not documented any changes in step locations in the Erlenbach during our prediction time frame. Thus, $\mathrm{h}_{\mathrm{a}} / \mathrm{p}_{\mathrm{u}}$ and $h_{a} / D_{m 84}$ will primarily depend on the mobile patch elevations, which vary with flow and sediment supply [Yager et al., 2007].

[61] We first attempted, using a variety of solver techniques (e.g., least squares, particle swarm algorithms) and our flow data in the Erlenbach, to solve our stress-partitioning equations for both coefficients $\left(C_{I}\right.$ and $\left.C_{m}\right)$ and allow these coefficients to vary with flow depth. However, none of the solver algorithms allowed us to determine unique and physically meaningful values of $C_{I}$ and $C_{m}$ for a given flow depth. We therefore calculated $\mathrm{C}_{\mathrm{m}}$ from data collected by Marcus et al. [1992] in an un-named steep stream with similar grain sizes to the Erlenbach's mobile sediment. This stream contained few boulders (see photos in the work of Marcus et al. [1992]) and we assumed its drag coefficient of the entire bed $\left(\mathrm{C}_{\mathrm{T}}\right)$ was a maximum estimate for $C_{m}$ in the Erlenbach. Thus, we assume $C_{m}$ may be relatively constant between steep channels, which is reasonable given that we only expect $\mathrm{C}_{\mathrm{m}}$ to vary with the relative submergence of the mobile sediment. Our calculation of $\mathrm{C}_{\mathrm{T}}$ therefore only included data points with $\mathrm{h}_{\mathrm{a}}$ / $\mathrm{D}_{84}$ values equal to those observed in the Erlenbach during sediment-transporting flows. Future work should focus on measurement of $\mathrm{C}_{\mathrm{m}}$ in other steep streams to test this assumption.

[62] We set equation (2) equal to equation (3), replaced $\mathrm{C}_{\mathrm{m}}$ with $\mathrm{C}_{\mathrm{T}}$, and solved for $\mathrm{C}_{\mathrm{T}}$ using the measured values of $U$ and hydraulic radius from Marcus et al. [1992]. We used the hydraulic radius $(R)$ instead of $h_{a}$ in these equations because $h_{a}$ was not reported. We set $C_{m}$ equal to the average value of $\mathrm{C}_{\mathrm{T}}(0.44 \pm 0.09)$, although $\mathrm{C}_{\mathrm{T}}$ displayed a power law relationship with $h_{a} / D_{84}\left(R^{2}\right.$ of 0.3 , Figure A1a). The statistical significance of this fit did not justify using a variable value for $C_{m}$. We also expect that $\mathrm{C}_{\mathrm{I}}$ is more likely to vary than $\mathrm{C}_{\mathrm{m}}$ because drag coefficients are only highly variable at low relative submergences [e.g., Bathurst, 1978; Bathurst et al., 1981; Thorne and Zevenbergen, 1985] and the mobile and immobile grains were fully and rarely submerged, respectively, during our measured flows.

[63] The variation in $C_{I}$ with $h_{a} / p_{u}$ was calculated using equation (1), solved for $C_{I}, C_{m}$ of 0.44 , and the measured values of $\mathrm{D}, \lambda_{\mathrm{x}}, \lambda_{\mathrm{w}}, \mathrm{Z}_{\mathrm{mu}}, \mathrm{h}_{\mathrm{a}}, \mathrm{U}, \mathrm{W}$, and $\mathrm{q}$ in the Erlenbach (Table 1). Although $C_{I}$ declined with increasing $h_{a} / p_{u}$, as expected, it did not vary smoothly because $\mathrm{w}$ and $\mathrm{h}_{\mathrm{a}}$ fluctuated irregularly with discharge in some cross sections (Figure A1b). We can substitute for $C_{I}$ in equation (1) using a power law fit between $C_{I}$ and $h_{a} / p_{u}$ :

$$
\mathrm{C}_{\mathrm{I}}=157{\frac{\mathrm{h}_{\mathrm{a}}}{\mathrm{p}_{\mathrm{u}}}}^{-1.6}
$$

[64] We compare the drag coefficients for the Erlenbach with those measured in streams with gradients greater than 3\% [Thompson and Campbell, 1979; Jarrett, 1984; Bathurst, 1985; Marcus et al., 1992; Lepp et al., 1993; MacFarlane and Wohl, 2003]. We lack the necessary data to determine $C_{I}$ in these channels and instead calculate $C_{T}$ using reported data $\left(\mathrm{h}_{\mathrm{a}}, \mathrm{U}\right.$, and grain size) in each stream and the method outlined above (for $\mathrm{C}_{\mathrm{m}}$ calibration). For a given $h_{a} / D_{84}$, the values of $C_{T}$ in the Erlenbach are similar to those from all other steep streams (Figure A1c). $\mathrm{C}_{\mathrm{T}}$ can be several orders of magnitude lower than $\mathrm{C}_{\mathrm{I}}$ because of the area scaling in our equations. $\mathrm{C}_{\mathrm{T}}=\mathrm{C}_{\mathrm{m}} \mathrm{A}_{\mathrm{m}}+\left(\mathrm{C}_{\mathrm{I}} \mathrm{A}_{\mathrm{IF}}\right) /$ $\mathrm{A}_{\mathrm{T}}$, where $\mathrm{A}_{\mathrm{IF}} / \mathrm{A}_{\mathrm{T}}$ and $\mathrm{C}_{\mathrm{m}} \mathrm{A}_{\mathrm{m}}$ were $\sim 0.02$ and 0.3 , respectively. Thus, the values of $C_{I}$ appear large because they are approximately equal to $C_{T}$ multiplied by $50 . C_{I}$ is higher in the Erlenbach than those values measured for isolated spheres in flume experiments because in the Erlenbach, it incorporates plunging flow over steps, local accelerations around boulders, and flow in jets and pools. All of these flow processes dissipate considerably greater energy than simple flow around spheres. Thus, we calculate $\mathrm{C}_{\mathrm{I}}$ as a bulk roughness coefficient as opposed to more commonly used equations for drag coefficients that incorporate pressure and velocity variations around individual objects.

[65] We tested our assumption of using a constant value of $\mathrm{C}_{\mathrm{m}}$ by fitting an equation to the measured values of $\mathrm{C}_{\mathrm{m}}$ and $h_{a} / D_{84}$ from Marcus et al. [1992]. We then use this equation, combined with our stress partitioning equations, to recalculate $C_{I}$ as a function of $h_{a} / p_{u}$ and $C_{m}$. Use of the variable $C_{m}$ caused the predicted stress borne by the mobile sediment to remain constant at moderate to high discharges in the Erlenbach (Figure A1d). This relationship was not reasonable because when used in a sediment transport equation, it would predict nearly constant sediment flux for a wide range of flow conditions. The stress borne by the mobile sediment should increase, like the total shear stress, with greater flow discharges. This occurs when we use a constant value for $\mathrm{C}_{\mathrm{m}}$ to calculate $\tau_{\mathrm{m}}$ (Figure A1d). 
(a)

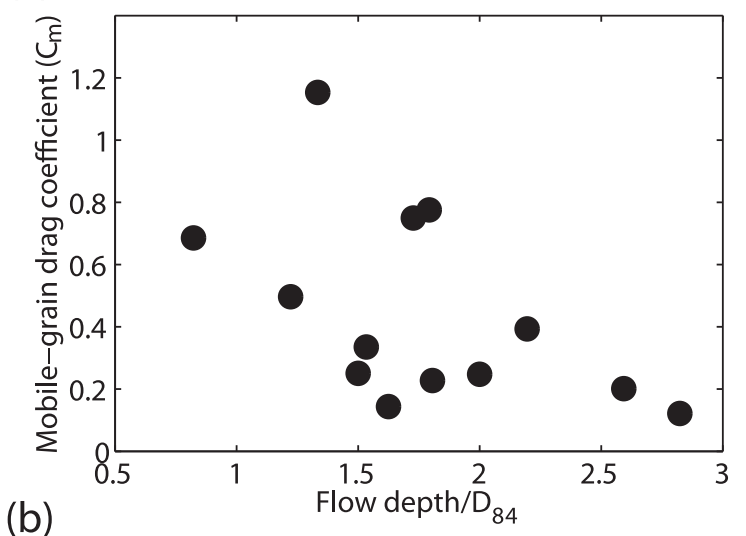

(b)

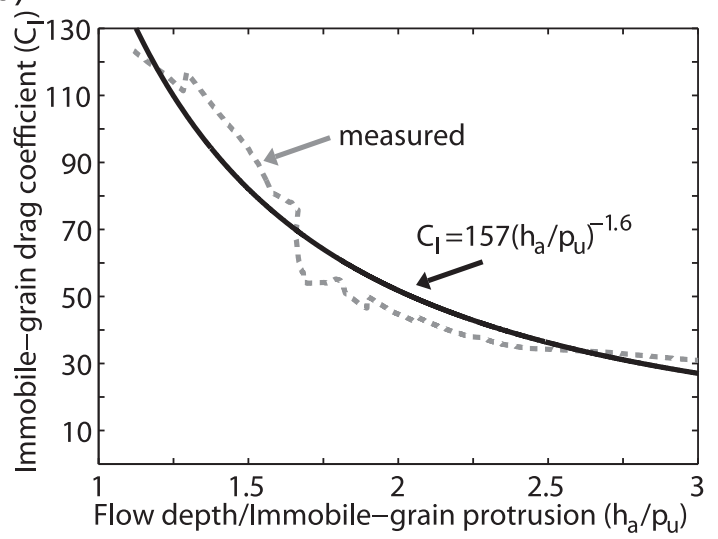

(c)

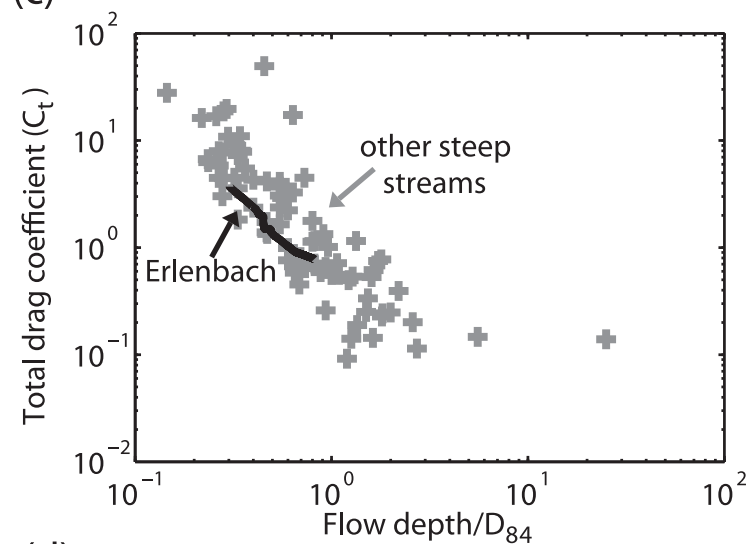

(d)

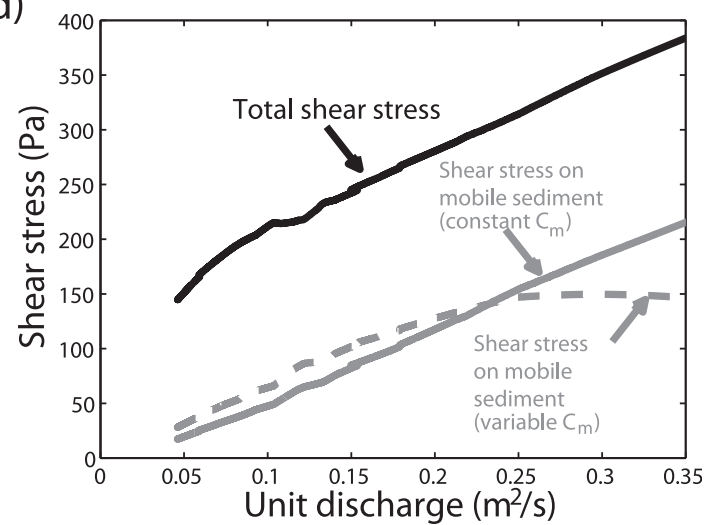

Figure A1. The drag coefficients for the (a) mobile sediment, (b) immobile grains, and (c) total bed as functions of relative submergence. The data in Figure A1a are from Marcus et al. [1992]. In Figure A1b, the dashed gray line shows the calculated values of $\mathrm{C}_{\mathrm{I}}$ and the solid black line is the best-fit equation to the data in the Erlenbach. In Figure A1c, the solid line is for the Erlenbach and gray crosses are for other steep streams [Thompson and Campbell, 1979; Jarrett, 1984; Bathurst, 1985; Marcus et al., 1992; Lepp et al., 1993; MacFarlane and Wohl, 2003]. In Figure A1d, the calculated shear stress in the Erlenbach is shown as a function of the unit discharge. Shown are the total shear stress (solid black line), and the stress borne by the mobile sediment for a constant (solid gray line), or variable (dashed gray line) value of $\mathrm{C}_{\mathrm{m}}$.

\section{Appendix A2: Hiding Function Calculation for the Erlenbach}

[66] We calibrated hiding functions for the Erlenbach using tracer particle (consisted of painted rocks and repeat photographs of a given location) movements during five low- to moderate- ( $71 \%$ of bankfull) flow events (see Yager [2006] for details on tracer measurements). The number of placed and transported tracer particles ranged from 290 and 23 , respectively, for the smallest event to 750 and 254 , respectively, for the largest event. The maximum grain size moved during an event can be used to calculate the critical shear stress and hiding function [e.g., Andrews, 1983; Carling, 1983; Mao et al., 2008]. The maximum mobile grain size did not regularly vary with shear stress in Erlenbach and was very sensitive to the location of tracer placement [see Yager, 2006]. To avoid these problems and to use a more statistically meaningful measurement of grain mobility, we assumed the mobile $\mathrm{D}_{84}$ of the tracer particles would represent the largest size moved during each event. We then divided this grain size by the $\mathrm{D}_{50}$ of the relatively mobile sediment or the $\mathrm{D}_{50}$ of the entire bed to obtain the grain size ratio $\left(\mathrm{D}_{\mathrm{i}} / \mathrm{D}_{50}\right.$ or $\left.\mathrm{D}_{\mathrm{i}} / \mathrm{D}_{50 \mathrm{~m}}\right)$ for each event. Hiding functions were fit between these ratios and the dimensionless peak total shear stress (fit with $\mathrm{D}_{\mathrm{i}} / \mathrm{D}_{50}$ ) or dimensionless peak stress on the mobile sediment (fit with $\mathrm{D}_{\mathrm{i}} / \mathrm{D}_{50 \mathrm{~m}}$ ) during each event that moved tracers (Figure A2).

\section{Appendix A3: Stress-Partitioning and the Original Parker Equations}

[67] The stress-partitioning equations are discussed in detail by Yager et al. [2007] and only a brief outline is given here. The total boundary shear stress $\left(\tau_{t}\right)$ is partitioned between the stress on the immobile grains $\left(\tau_{\mathrm{I}}\right)$ and the mobile sediment $\left(\tau_{\mathrm{m}}\right)$,

$$
\tau_{\mathrm{t}}=\frac{\tau_{\mathrm{I}} \mathrm{A}_{\mathrm{IP}}+\tau_{\mathrm{m}} \mathrm{A}_{\mathrm{m}}}{\mathrm{A}_{\mathrm{t}}},
$$

where $A_{t}$ is the total bed area, and $A_{m}$ and $A_{I P}$ are the total bed-parallel areas of the mobile and immobile grains, 


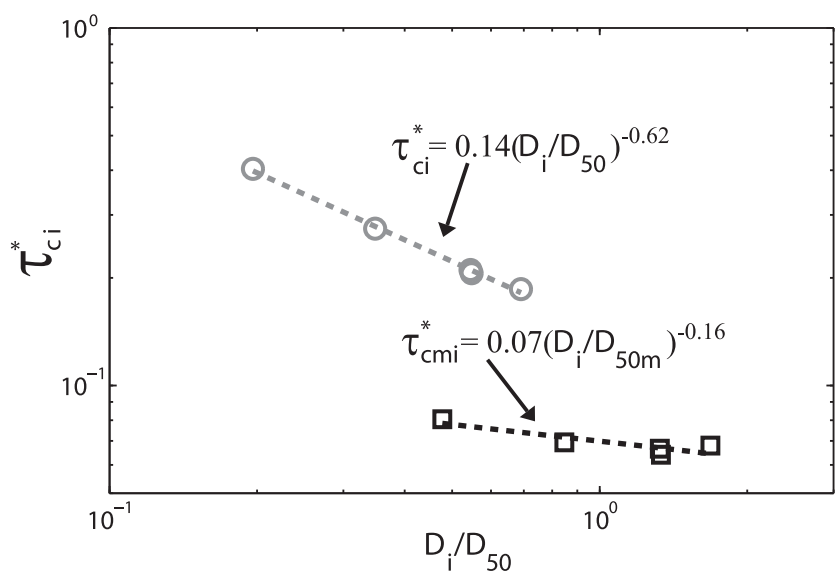

Figure A2. Dimensionless critical shear stress as a function of the relative grain size $\left(D_{i} / D_{50}\right)$ in the Erlenbach. Hiding function fits to tracer particle movements are shown for both the mobile (squares) and total (circles) bed sediment. The dimensionless critical shear stresses were calculated using the stress borne by the mobile sediment (squares) and the total shear stress (circles).

respectively. $\tau_{\mathrm{t}}$ and $\tau_{\mathrm{m}}$ are given by equations (2) and (3), respectively, and $\tau_{\mathrm{I}}$ is calculated using

$$
\tau_{\mathrm{I}}=\frac{\rho \mathrm{A}_{\mathrm{IF}} \mathrm{C}_{\mathrm{I}} \mathrm{U}^{2}}{2 \mathrm{~A}_{\mathrm{IP}}},
$$

where $C_{I}$ and $A_{I F}$ are the drag coefficient and bed-perpendicular area of the immobile grains. $\mathrm{A}_{\mathrm{IF}}$ is given by

$$
\begin{aligned}
A_{I F} & =\left[\left(h_{a}+z_{m u}-\frac{D}{2}\right) \sqrt{\left(h_{a}+z_{m u}\right) D-\left(h_{a}+z_{m u}\right)^{2}}\right. \\
& \left.+\frac{D^{2}}{4} \sin ^{-1}\left(2\left[\frac{h_{a}+z_{m u}}{D}\right]-1\right)-\left(z_{m u}-\frac{D}{2}\right) \sqrt{z_{m u} D-z_{m u}^{2}}\right] \frac{w}{D} \\
& -\frac{D w}{4} \sin ^{-1}\left(\frac{2 z_{m u}}{D}-1\right) \text { when } h+z_{m} \leq D
\end{aligned}
$$$$
\mathrm{A}_{\mathrm{IF}}=\left[\frac{\pi \mathrm{D}^{2}}{8}-\left(\mathrm{z}_{\mathrm{mu}}-\frac{\mathrm{D}}{2}\right) \sqrt{\mathrm{z}_{\mathrm{mu}} \mathrm{D}-\mathrm{z}_{\mathrm{mu}}^{2}}-\frac{\mathrm{D}^{2}}{4} \sin ^{-1}\left(\frac{2 \mathrm{z}_{\mathrm{mu}}}{\mathrm{D}}-1\right)\right] \frac{\mathrm{w}}{\mathrm{D}},
$$$$
\text { when } \mathrm{h}+\mathrm{z}_{\mathrm{m}} \geq \mathrm{D} \text {, }
$$

where $\mathrm{D}$ is the median grain size of the immobile grains, $\mathrm{w}$ is the channel width, $h_{a}$ is the average flow depth, and $z_{m u}$ is the bed-perpendicular height of the mobile sediment (see section 2.1 for details). We combine equations (2), (3), (A16), and (A2)-(A4) to obtain the solution given in equation (1).

[68] The dimensionless critical shear stress is given by

$$
\tau_{\mathrm{c}}^{*}=\frac{\tau_{\mathrm{c}}}{\left(\rho_{\mathrm{s}}-\rho\right) \mathrm{gD}_{50}},
$$

where is $\tau_{\mathrm{c}}^{*}$ is the critical shear stress and $\mathrm{D}_{50}$ is the median grain size.
[69] In our modified Parker equations below, we use the constants and notation given by Parker [1990] for all equations except (A9), in which we use notation from Parker [2008]. The bed is divided into $N$ grain size classes with characteristic diameters $\left(D_{i}\right)$ where $i$ ranges from 1 to $N$. The geometric mean size of the relatively mobile sediment $\left(\mathrm{D}_{\text {sgm }}\right)$ is given by

$$
\ln \mathrm{D}_{\mathrm{sgm}}=\sum_{\mathrm{i}=1}^{\mathrm{N}} \mathrm{F}_{\mathrm{mi}} \ln \mathrm{D}_{\mathrm{i}}
$$

where $F_{m i}$ is the volume fraction of the relatively mobile sediment in the $i$ th grain-size class. The arithmetic standard deviation (in $\phi$ units) of the relatively mobile sediment $\left(\sigma_{\phi \mathrm{m}}\right)$ is

$$
\sigma_{\phi \mathrm{m}}^{2}=\sum_{\mathrm{i}=1}^{\mathrm{N}}\left(\frac{\ln \left[\mathrm{D}_{\mathrm{i}} / \mathrm{D}_{\mathrm{sgm}}\right]}{\ln 2}\right)^{2} \mathrm{~F}_{\mathrm{mi}}
$$

The dimensionless shear stress borne by the mobile sediment $\left(\tau_{\mathrm{sgm}}^{*}\right)$ is given by

$$
\tau_{\mathrm{sgm}}^{*}=\frac{\tau_{\mathrm{m}}}{\rho \mathrm{R}_{\mathrm{s}} \mathrm{gD}},
$$

where $R_{s}$ is the dimensionless submerged specific gravity of sediment and $\rho_{\mathrm{s}}$ is the sediment density. The hiding function for the mobile sediment $\left(\phi_{\mathrm{mi}}\right)$ is

$$
\phi_{\mathrm{mi}}=\omega_{\mathrm{m}} \phi_{\mathrm{sgom}}\left(\frac{\mathrm{D}_{\mathrm{i}}}{\mathrm{D}_{\mathrm{sgm}}}\right)^{-0.0951},
$$

where

$$
\phi_{\mathrm{sgom}}=\frac{\tau_{\mathrm{sgm}}^{*}}{\tau_{\mathrm{rggo}}^{*}}
$$

and $\tau_{\text {rsgo }}^{*}$ is a dimensionless reference stress $(0.0386$, in the original Parker equation). The empirical function $\omega_{\mathrm{m}}$ is

$$
\omega_{\mathrm{m}}=1+\frac{\sigma_{\phi \mathrm{m}}}{\sigma_{\phi \mathrm{O}}\left(\phi_{\mathrm{sgom}}\right)}\left[\omega_{\mathrm{O}}\left(\phi_{\mathrm{sgom}}\right)-1\right],
$$

where $\sigma_{\phi \mathrm{O}}\left(\phi_{\text {sgom }}\right)$ and $\omega_{\mathrm{O}}\left(\phi_{\text {sgom }}\right)$ are graphical functions illustrated by Parker [1990]. The dimensionless bed load transport rate $\left(\mathrm{W}_{\mathrm{msi}}^{*}\right)$ of each ith size class in the mobile sediment is

$$
\mathrm{W}_{\mathrm{msi}}^{*}=0.00218 \mathrm{G}\left(\phi_{\mathrm{mi}}\right)
$$

and the empirical function $\mathrm{G}\left(\phi_{\mathrm{mi}}\right)$ is

$\mathrm{G}\left(\phi_{\mathrm{mi}}\right)=\left\{\begin{array}{l}5474\left(1-\frac{0.853}{\phi_{\mathrm{mi}}}\right)^{4.5} \text { for } \phi_{\mathrm{mi}}>1.59 \\ \exp \left[14.2\left(\phi_{\mathrm{mi}}-1\right)-9.28\left(\phi_{\mathrm{mi}}-1\right)^{2}\right] \text { for } 1 \leq \phi_{\mathrm{mi}} \leq 1.59 \\ \phi_{\mathrm{mi}} \text { for } \phi_{\mathrm{mi}}<1 .\end{array}\right.$ 
Equation (A13) is based on empirical fits to bed load transport data from Oak Creek [Parker, 1990]. The volumetric transport rate per unit width $\left(\mathrm{q}_{\mathrm{mi}}\right)$ for each $i$ th size class in the relatively mobile sediment is

$$
\mathrm{q}_{\mathrm{mi}}=\frac{{\sqrt{\frac{\tau_{\mathrm{m}}}{\rho}}}^{3} \mathrm{~F}_{\mathrm{mi}} \mathrm{W}_{\mathrm{msi}}^{*}}{\mathrm{R}_{\mathrm{s}} \mathrm{g}} .
$$

The total transport rate per unit width $\left(\mathrm{q}_{\mathrm{Tm}}\right)$ of all grain sizes in the mobile sediment is

$$
\mathrm{q}_{\mathrm{Tm}}=\left(\sum_{\mathrm{i}=1}^{\mathrm{N}} \mathrm{q}_{\mathrm{bmi}}\right) \frac{\mathrm{A}_{\mathrm{m}}}{\mathrm{A}_{\mathrm{t}}},
$$

where the transport rate is scaled by the proportion of the bed covered by relatively mobile sediment $\left(A_{m} / A_{t}\right)$. The total unit bed area $\left(\mathrm{A}_{t}\right)$ is the product of the channel width and $\lambda_{\mathrm{x}}$ (Figure 2). The area occupied by relatively mobile sediment $\left(\mathrm{A}_{\mathrm{m}}\right)$ is

$$
\mathrm{A}_{\mathrm{m}}=\mathrm{w} \lambda_{\mathrm{x}}-\mathrm{A}_{\mathrm{IP}},
$$

which is the difference between $A_{t}$ and the total bed-parallel area occupied by immobile grains $\left(\mathrm{A}_{\mathrm{IP}}\right)$. The later is calculated as the bed-parallel area of one immobile grain $\left(\lambda_{\mathrm{w}} \mathrm{D}\right)$ multiplied by the number of immobile grains $(\mathrm{w} / \mathrm{D})$ within $\mathrm{A}_{\mathrm{t}}$.

[70] The fraction of bed load in the $i$ th grain-size class $\left(\mathrm{p}_{\mathrm{mi}}\right)$ is

$$
\mathrm{p}_{\mathrm{mi}}=\frac{\mathrm{q}_{\mathrm{mi}}}{\frac{\mathrm{q}_{\mathrm{Tm}} \mathrm{A}_{\mathrm{t}}}{\mathrm{A}_{\mathrm{m}}}} .
$$

The original Parker [1990] sediment transport equations are shown below. The geometric-mean size $\left(\mathrm{D}_{\mathrm{sg}}\right)$ of the surface sediment is

$$
\ln \mathrm{D}_{\mathrm{sg}}=\sum_{\mathrm{i}=1}^{\mathrm{N}} \mathrm{F}_{\mathrm{i}} \ln \mathrm{D}_{\mathrm{i}},
$$

where $F_{i}$ is the volume fraction of the sediment in the $i$ th grain-size class. The arithmetic standard deviation of the surface grain-size distribution $\left(\sigma_{\phi}\right)$ is

$$
\sigma_{\phi}^{2}=\sum_{\mathrm{i}=1}^{\mathrm{N}}\left(\frac{\ln \left(\mathrm{D}_{\mathrm{i}} / \mathrm{D}_{\mathrm{sg}}\right)}{\ln 2}\right)^{2} \mathrm{~F}_{\mathrm{i}}
$$

and the dimensionless shear stress is

$$
\tau_{\mathrm{sg}}^{*}=\frac{\tau_{\mathrm{t}}}{\rho \mathrm{R}_{\mathrm{s}} \mathrm{g} \mathrm{D}_{\mathrm{sg}}} .
$$

The hiding function for the entire bed $\left(\phi_{\mathrm{i}}\right)$ is

$$
\phi_{\mathrm{i}}=\omega \phi_{\mathrm{sgo}}\left(\frac{\mathrm{D}_{\mathrm{i}}}{\mathrm{D}_{\mathrm{sg}}}\right)^{-0.0951},
$$

where

$$
\phi_{\mathrm{sgo}}=\frac{\tau_{\mathrm{sg}}^{*}}{\tau_{\mathrm{ssrg}}^{*}}
$$

and $\tau_{\text {ssrg }}^{*}$ is the dimensionless reference stress $(0.0386)$. The empirical function $\omega$ is

$$
\omega=1+\frac{\sigma_{\phi}}{\sigma_{\mathrm{O}}\left(\phi_{\mathrm{sgo}}\right)}\left[\omega_{\mathrm{O}}\left(\phi_{\mathrm{sgo}}\right)-1\right],
$$

where $\sigma_{\mathrm{O}}\left(\phi_{s g_{0}}\right)$ and $\omega_{\mathrm{O}}\left(\phi_{\mathrm{sgo}}\right)$ are graphical functions illustrated by Parker [1990]. The dimensionless bed load transport rate $\left(\mathrm{W}_{\mathrm{si}}^{*}\right)$ for each $i$ th size class is

$$
\mathrm{W}_{\mathrm{si}}^{*}=0.00218 \mathrm{G}\left(\phi_{\mathrm{i}}\right),
$$

where the empirical function $\mathrm{G}\left(\phi_{\mathrm{i}}\right)$ is

$$
\mathrm{G}\left(\phi_{\mathrm{i}}\right)=\left\{\begin{array}{l}
5474\left(1-\frac{0.853}{\phi_{\mathrm{i}}}\right)^{4.5} \text { for } \phi_{\mathrm{i}}>1.59 \\
\exp \left[14.2\left(\phi_{\mathrm{i}}-1\right)-9.28\left(\phi_{\mathrm{i}}-1\right)^{2}\right] \text { for } 1 \leq \phi_{\mathrm{i}} \leq 1.59 \\
\phi_{\mathrm{i}} \text { for } \phi_{\mathrm{i}}<1
\end{array}\right.
$$

The volumetric transport rate per unit width $\left(\mathrm{q}_{\mathrm{i}}\right)$ for each grain size is

$$
\mathrm{q}_{\mathrm{i}}=\frac{\mathrm{w}_{\mathrm{si}}^{*}\left(\tau_{\mathrm{t}} / \rho\right)^{1.5} \mathrm{~F}_{\mathrm{i}}}{\mathrm{R}_{\mathrm{s}} \mathrm{g}}
$$

and the total volumetric transport rate per unit width $\left(\mathrm{q}_{\mathrm{T}}\right)$ is

$$
\mathrm{q}_{\mathrm{T}}=\sum_{\mathrm{i}=1}^{\mathrm{N}} \mathrm{q}_{\mathrm{i}} \text {. }
$$

The fraction of bed load in the $i$ th grain-size class $\left(\mathrm{p}_{\mathrm{i}}\right)$ is

$$
\mathrm{p}_{\mathrm{i}}=\frac{\mathrm{q}_{\mathrm{i}}}{\mathrm{q}_{\mathrm{T}}} .
$$

\section{Appendix A4: Measurements and Calculations Needed to Apply Modified Parker Equation}

[71] Bed load transport can be determined in any steep stream using a series of calculations, eight reach-averaged variables $\left(w, S, q, D, p_{u}\right.$, grain size distribution of mobile sediment, $\lambda_{\mathrm{x}}$ and $\left.\lambda_{\mathrm{w}}\right)$, and two drag coefficients $\left(\mathrm{C}_{\mathrm{m}}\right.$ and $\mathrm{C}_{\mathrm{I}}$ ). A measured flow discharge (q) or the flow discharge hydrograph are needed to calculate sediment flux. As discussed in section 5.4, the channel width (w) and slope (S) can be obtained from simple cross-sectional surveys and longitudinal profiles of a stream. The channel bed should then be mapped into mobile and immobile patches, which are denoted using the step classification criteria outlined in section 3.1.2. The downstream distance between each step $\left(\lambda_{\mathrm{x}}\right)$ and downstream step length $\left(\lambda_{\mathrm{w}}\right)$ can be determined using a measurement tape (see Figure 2 for the definition of these parameters). The upstream step protrusion could be measured using detailed surveying equipment (e.g., total station, DGPS, ground-based LiDAR) or a ruler. This parameter should be measured multiple times on every step to 
ensure that the inherent variability in protrusion is captured. All boulders and/or cobbles within the immobile steps should be measured and used to obtain the median grain size of the immobile sediment. Finally, multiple pebble counts should be conducted on the relatively mobile sediment and these counts should be aerially weighted to obtain a composite grain size distribution. The reach-averaged height of the relatively mobile sediment $\left(z_{m u}\right)$ is $D-p_{u}$. The reached-averaged values for $\mathrm{w}, \mathrm{S}, \mathrm{D}, \mathrm{z}_{\mathrm{mu}}, \lambda_{\mathrm{x}}$, and $\lambda_{\mathrm{w}}$ and a given flow discharge (or flow hydrograph) are then used to iterate a solution for the reach-averaged flow depth $\left(h_{a}\right)$ using equations (1) and (A4). In these calculations either our calibrated (see section 3.1.3) or locally calibrated (to the stream of interest) values for the drag coefficients $\left(C_{m}\right.$ and $\mathrm{C}_{\mathrm{I}}$ ) need to be used. The flow velocity is calculated as $\mathrm{q} / \mathrm{h}_{\mathrm{a}}$ and is used to determine the stress borne by mobile sediment from equation (3). Then, one should step through equations (A6)-(A8) and determine which hiding function is appropriate for a given stream. The Erlenbach and original Parker hiding functions are given by equations (5) and (A9), respectively. Note that the dimensionless reference stress is different between these equations. Once the hiding function has been chosen, one can step through equations (A10)-(A17) to determine the sediment flux for a given discharge. A MATLAB script, which will only require the input parameters of $\mathrm{w}, \mathrm{S}$, flow hydrograph, $\mathrm{D}, \mathrm{p}_{\mathrm{u}}$, grain size distribution of mobile sediment, $\lambda_{\mathrm{x}}$, and $\lambda_{\mathrm{w}}$, will be made available at https://sites.google.com/site/emyager/home. This script uses our calibrated drag coefficients and gives the user an option to choose from a range of hiding functions.

\section{Definition of Symbols}

$\mathrm{A}_{\mathrm{IF}} \quad$ bed-perpendicular area of immobile grains

$\mathrm{A}_{\mathrm{IP}}$ bed-parallel area occupied of immobile grains

$A_{m}$ bed-parallel area of mobile sediment

$\mathrm{A}_{\mathrm{t}} \quad$ total bed area

$\mathrm{C}_{\mathrm{m}} \quad$ drag coefficient for the mobile sediment

$\mathrm{C}_{\mathrm{I}}$ drag coefficient for the immobile grains

$\mathrm{C}_{\mathrm{T}} \quad$ drag coefficient for the entire bed

$\mathrm{D}$ mean immobile-grain diameter

$\mathrm{D}_{50} \quad$ median grain size of entire bed

$\mathrm{D}_{50 \mathrm{~m}}$ median grain size of mobile sediment

$\mathrm{D}_{84 \mathrm{~m}}$ 84th percentile of the grain-size distribution of the relatively mobile sediment

$D_{84}$ 84th percentile of the grain-size distribution of the entire bed

$\mathrm{D}_{\mathrm{i}} \quad$ characteristic grain size in the $i$ th grain-size class

$D_{\text {sg }}$ geometric mean size of the entire bed

$\mathrm{D}_{\mathrm{sgm}}$ geometric mean size of the relatively mobile sediment

g acceleration due to gravity

$\mathrm{h}_{\mathrm{a}}$ average flow depth

$\mathrm{F}_{\mathrm{mi}}$ proportion of the relatively mobile sediment in the $i$ th grain-size class

$F_{i}$ proportion of the entire bed sediment that is in the $i$ th grain-size class

$\mathrm{p}_{\mathrm{i}} \quad$ fraction of the predicted bed load that is in the $i$ th grain-size class (original Parker)

$\mathrm{p}_{\mathrm{mi}} \quad$ fraction of the predicted bed load that is in the $i$ th grain-size class (modified Parker) $\mathrm{p}_{\mathrm{u}}$ portion of immobile grains that protrude above the mobile bed surface that is upstream of the steps

$\mathrm{q}$ discharge per unit width

$\mathrm{q}_{\mathrm{i}} \quad$ volumetric sediment transport rate per unit width of the mobile sediment in the $i$ th grain-size class (original Parker)

$\mathrm{q}_{\mathrm{mi}} \quad$ volumetric sediment transport rate per unit width of the mobile sediment in the $i$ th grain-size class (modified Parker)

$\mathrm{q}_{\mathrm{T}}$ total volumetric sediment transport rate per unit width of the mobile sediment (original Parker)

$\mathrm{q}_{\mathrm{Tm}}$ total volumetric sediment transport rate per unit width of the mobile sediment (modified Parker)

$\mathrm{R}$ hydraulic radius

$\mathrm{R}_{\mathrm{s}}$ dimensionless submerged specific gravity of sediment

$\mathrm{S}$ reach-average water surface slope

$\mathrm{U}$ reach-average velocity

w channel width

w/D number of immobile elements on the bed

$\mathrm{W}_{\mathrm{si}}^{*} \quad$ dimensionless sediment transport rate of the mobile sediment in the $i$ th grain-size class (original Parker)

$\mathrm{W}_{\mathrm{msi}}^{*} \quad$ dimensionless sediment transport rate of the mobile sediment in the $i$ th grain-size class (modified Parker)

$\mathrm{Z}_{\mathrm{mu}} \quad$ average bed-perpendicular height of the (upstream) mobile sediment above the base of the immobile grains

$\lambda_{\mathrm{x}} \quad$ downstream immobile-grain spacing

$\lambda_{\mathrm{y}} \quad$ cross-stream immobile-grain spacing

$\lambda_{\mathrm{w}}$ downstream length of immobile-grain steps

$\lambda / \mathrm{D}$ dimensionless immobile-grain spacing

$\rho$ density of water

$\rho_{\mathrm{s}} \quad$ density of sediment

$\sigma_{\phi} \quad$ arithmetic standard deviation of the entire bed

$\sigma_{\phi \mathrm{m}}$ arithmetic standard deviation of the relatively mobile sediment

$\phi \quad$ hiding function for the entire bed

$\phi_{\mathrm{mi}}$ hiding function for the mobile sediment

$\tau_{\text {I }} \quad$ stress borne by immobile grains

$\tau_{\mathrm{m}} \quad$ stress borne by mobile sediment

$\tau_{\text {rsgo }}^{*} \quad$ reference dimensionless shear stress

$\tau_{\mathrm{sg}}^{*} \quad$ dimensionless stress borne by the entire bed (original Parker)

$\tau_{\mathrm{sgm}}^{*} \quad$ dimensionless stress borne by the mobile sediment (modified Parker)

$\tau_{\mathrm{t}} \quad$ total boundary shear stress

[72] Acknowledgments. Funding for this research was provided by a CA Water Resources grant to W. Dietrich, an AGU Horton Graduate Award to E. Yager, and the Swiss Federal Research Institute WSL. Invaluable field assistance was provided by M. Swartz, A. Densmore, D. Frank, J. Sanders, S. Araki, J. Stock, and B. Fritschi. Thoughtful reviews by M. Stacey, A. Zimmermann, J. Turowski, L. Mao, James Brasington, and two anonymous reviewers improved earlier versions of this manuscript.

\section{References}

Abrahams, A. D., and J. F. Atkinson (1993), Relation between grain velocity and sediment concentration in overland flow, Water Resour. Res., 29, 3021-3028. 
Aguirre-Pe, J. (1975), Incipient erosion in high gradient open channel flow with artificial roughness elements, Proc. 16th Congr. Int. Assoc. Hydraul. Res., San Paulo, Brazil, 2, 137-180.

Aguirre-Pe, J., and R. Fuentes (1991), Movement of big particles in steep, macro-rough streams, Proc. 24th Congr. Int. Assoc. Hydraul. Res., Madrid, Spain, $A$, 149-158.

Andrews, E. D. (1983), Entrainment of gravel from naturally sorted riverbed material, Geol. Soc. Amer. Bull., 94, 1225-1231.

Ashida, K., and M. Bayazit (1973), Initiation of motion and roughness of flows in steep channels, Intl. Assoc. Hydraul. Res. Proc. 15th Congress, Istanbul, Turkey, 1, 475-484.

Ashworth, P. J., and R. I. Ferguson (1989), Size-selective entrainment of bed load in gravel bed streams, Water Resour. Res., 25, 627 634.

Ashworth, P. J., R. I. Ferguson, P. E. Ashmore, C. Paola, D. M. Powell, and K. L. Prestegaard (1992), Measurements in a braided river chute and lobe 2: Sorting of bedload during entrainment, transport, and deposition, Water Resour. Res., 28, 1887-1896.

Bartnick, W. (1991), Determination of the critical conditions of incipient motion of bed load in mountain rivers, in Fluvial Hydraulics in Mountain Regions, edited by A. Armanini and G. Di Silvio, pp. 83-88, SpringerVerlag, Berlin, Germany.

Bathurst, J. C. (1978), Flow resistance of large-scale roughness, J. Hydraul. Div., 104, 1587-1603.

Bathurst, J. C. (1985), Flow resistance estimation in mountain rivers, $J$. Hydraul. Eng., 111, 625-643.

Bathurst, J. C., R. M. Li, and D. B. Simons (1981), Resistance equation for large-scale roughness, J. Hydraul. Eng., 107, 1593-1613.

Bathurst, J. C., G. J. L. Leeks, and M. D. Newson (1986), Field measurements for hydraulic and geomorphological studies of sediment transport. The special problems of mountain streams, paper presented at Symposium on Measuring Techniques in Hydraulic Research, Delft, Netherlands, pp. 137-151.

Bathurst, J. C., W. H. Graf, and H. H. Cao (1987), Bed load discharge equations for steep mountain rivers, in Sediment Transport in Gravel-Bed Rivers, edited by C. R. Thorne, J. C. Bathurst, and R. D. Hey, pp., 453-477, John Wiley, N. Y.

Benda, L., and T. Dunne (1997), Stochastic forcing of sediment routing and storage in channel network, Water Resour. Res., 33, 2865-2880.

Buffington, J. M., and D. R. Montgomery (1997), A systematic analysis of eight decades of incipient motion studies, with special reference to gravel-bedded rivers, Water Resour. Res., 33, 1993-2029.

Buffington, J. M., and D. R. Montgomery (1999a), Effects of sediment supply on surface textures of gravel-bed rivers, Water Resour. Res., 35, 3523-3530.

Buffington, J. M., and D. R. Montgomery (1999b), A procedure for classifying textural facies in gravel-bed rivers, Water Resour. Res., 35, 1903 1914.

Byrd, T. C., and D. J. Furbish (2000), Magnitude of deviatoric terms in vertically averaged flow equations, Earth Surf. Processes Landforms, 25, 319-328.

Byrd, T. C., D. J. Furbish, and J. Warburton (2000), Estimating depthaveraged velocities in rough channels, Earth Surf. Processes Landforms, $25,167-173$

Calkins, D., and T. Dunne (1970), A salt tracing method for measuring channel velocities in small mountain streams, J. Hydrology, 11, 379392

Carling, P. A. (1983), Threshold of coarse sediment transport in broad and narrow natural streams, Earth Surf. Processes Landforms, 8, 1-18.

Church, M., and A. Zimmermann (2007), Form and stability of step-pool channels: Research progress, Water Resour. Res., 43, W03415, doi:10.1029/2006WR005037.

Curran, J. H., and E. E. Wohl (2003), Large woody debris and flow resistance in step-pool channels, Cascade Range, Washington, Geomophology, 51, 141-157.

D'Agostino, V., and M. A. Lenzi (1999), Bedload transport in the instrumented catchment of the Rio Cordon part II: Analysis of the bedload rate, Catena, 36, 191-204.

Day, T. J. (1977a), Observed mixing lengths in mountain streams, J. Hydrology, 35, 125-136.

Day, T. J. (1977b), Field procedures and evaluation of a slug dilution gauging method in mountain streams, J. Hydrology (New Zealand), 16, 113-133.

Dietrich, W. E., P. A. Nelson, E. Yager, J. G. Venditti, M. P. Lamb, and L. Collins (2005), Sediment patches, sediment supply, and channel morphology, in River Coastal and Estuarine Morphodynamics, edited by G. Parker and M. H. Garcia, pp. 79-90, Taylor and Francis, London, U. K.

Ferguson, R. I. (2003), The missing dimension: Effects of lateral variation on 1-D calculations of fluvial bedload transport, Geomorphology, 56, 114, doi:10.1016/S0169-555X(03)00042-4.

Ferguson, R. I., J. R. Cudden, T. B. Hoey, and S. P. Rice (2006), River system discontinuities due to lateral inputs: generic styles and controls, Earth Surface Processes Landforms, 31, 1149-1166.

Fernandez Luque, R. F., and R. Van Beek (1976), Erosion and transport of bedload sediment, J Hydraul. Res., 14, 127-144.

Flammer, G. H., J. P. Tullis, and E. S. Mason (1970), Free surface, velocity gradient flow past hemisphere, J. Hydraul. Div., HY7, 1485-1502.

Garcia, C., J. B. Laronne, and M. Sala (1999), Variable source areas of bedload in a gravel-bed stream, J. Sedimentary Res., 6, 27-31.

Gill, M. A. (1979), Hydraulics of rectangular vertical drop structures, $J$. Hydraul. Res., 17, 289-302.

Gomi, T., and R. C. Sidle (2003), Bed load transport in managed steepgradient headwater streams of southeastern Alaska, Water Resour. Res., 12(12), 1336, doi:10.1029/2003WR002440.

Graf, W. H., and L. Suszka (1987), Sediment transport in steep channels, J. Hydrosci. Hydraul. Eng., 5(1), 11-26.

Hegg, C., B. W. McArdell, and A. Badoux (2006), One hundred years of mountain hydrology in Switzerland by the WSL, Hydrol. Processes, 20, 371-376, doi: $10.1002 /$ hyp.6055.

Hoffman, G. J. C. M. (1998), Jet scour in equilibrium phase, J. Hydraul. Eng., 124, 430-437.

Howard, A. D., W. E. Dietrich, and M. A. Seidl (1994), Modeling fluvial erosion on regional to continental scales, J. Geophys. Res., 99, 13,971$13,986$.

James, C. S., A. G. Main, and J. Moon (2001), Enhanced energy dissipation in stepped chutes, Water Mar. Eng., 4, 277-280.

Jarrett, R. D. (1984), Hydraulics of high-gradient streams, J. Hydraul. Eng., $110,1519-1539$

Kalinske, A. (1943), The role of turbulence in river hydraulics, Bull. Univ. Iowa Studies Eng. 27, 266-279.

Kean, J. W., and J. D. Smith (2006a), Form drag in rivers due to small-scale natural topographic features: 1. Regular sequences, J. Geophys. Res., 111, F04009, doi:10.1029/2006JF000467.

Kean, J. W., and J. D. Smith (2006b), Form drag in rivers due to small-scale natural topographic features: 2. Irregular sequences, J. Geophys. Res., 111, F04010, doi:10.1029/2006JF000490.

Kean, J. W., R. A. Kuhnle, J. D. Smith, C. V. Alonso, and E. J. Langendoen (2009), Test of a method to calculate near-bank velocity and boundary shear stress, J. Hyd. Eng., 135, 588-601.

Kunle, R. A. (1980), Bed-surface size changes in gravel-bed channels, $J$. Hydraul. Eng., 115, 731-741.

Lamb, M. P., W. E. Dietrich, and J. G. Venditti (2008), Is the critical Shields stress for incipient sediment motion dependent on channel-bed slope?, J. Geophys. Res., 113, F02008, doi:10.1029/2007JF000831.

Lee, A. J., and R. I. Ferguson (2002), Velocity and flow resistance in steppool streams, Geomorphology, 46, 59-71.

Lenzi, M. A. (2001), Step-pool evolution in the Rio Cordon, northeastern Italy, Earth Surf. Processes Landforms, 26, 991-1008.

Lenzi, M. A. (2004), Displacement and transport of marked pebbles, cobbles and boulders during floods in a steep mountain stream, Hydrol. Processes, 18, 1899-1914.

Lenzi, M. A., L. Mao, and F. Comiti (2006), When does bedload transport begin in steep boulder-bed streams? Hydrol. Processes, 20, 3517-3533, doi:10.1002/hyp.6168.

Lenzi, M. A., V. D. D’Agostino, and P. Billi (1999), Bedload transport in the instrumented catchment of the Rio Cordon Part I: Analysis of bedload records, conditions and threshold of bedload entrainment, Catena, $36,171-190$

Lenzi, M. A., L. Mao, and F. Comiti (2004), Magnitude-frequency analysis of bedload data in an Alpine boulder bed stream, Water Resour. Res., 40, W07201, doi:10.1029/2003WR002961.

Lepp, L. R., C. J. Koger, and J. A. Wheeler (1993), Channel erosion in steep gradient, gravel-paved streams, Bull. Assoc. Eng. Geol., 30, 434-454.

Li, G., and A. D. Abrahams (1996), Correction factors in the determination of mean velocity of overland flow, Earth Surf. Processes Landforms, 21, 509-515.

Luk, S. H., and W. Merz (1992), Use of the salt tracing technique to determine the velocity of overland flow, Soil Tech., 5, 289-301. 
MacFarlane, W. A., and E. Wohl (2003), Influence of step composition on step geometry and flow resistance in step-pool streams of the Washington Cascades, Water Resour. Res., 39(2), 1037, doi:10.1029/ 2001WR001238.

Mao, L., and M. A. Lenzi (2007), Sediment mobility and bedload transport conditions in an alpine stream, Hydrol. Processes, 21, 1882-1891, doi: $10.1002 /$ hyp. 6372 .

Mao, L., G. P. Uyttendaele, A. Iroume, and M. A. Lenzi (2008), Field based analysis of sediment entrainment in two high gradient streams located in Alpine and Andine environments, Geomorphology, 93, 368-383.

Marion, D. A., and F. Weirich (2003), Equal-mobility bed load transport in a small, step-pool channel in the Ouachita Mountains, Geomorphology, 55, 139-154, doi:10.1016/S0169-555X(03)00137-5.

Marcus, W. A., K. Roberts, L. Harvey, and G. Tackman (1992), An evaluation of methods for estimating Manning's $\mathrm{n}$ in small mountain streams, Mountain Res. Dev., 12, 227-239.

Moore, W. L. (1943), Energy loss at the base of free overfall, Trans. Am. Soc. Civ. Eng., 108, 1343-1360.

Mueller, E. R., J. Pitlick, and J. Nelson (2005), Variation in the reference shields stress for bed load transport in gravel-bed streams and rivers, Water Resour. Res., 41, W04006, doi:10.1029/2004WR003692.

Mueller, E. N., R. J. Batalla, C. Garcia, and A. Bronstert (2008), Modeling bed-load rates from fine grain-size patches during small floods in a gravel-bed river, J. Hydraul. Eng., 134, 1430-1439.

Nelson, J. M., R. L. Shreve, S. R. McLean, and T. G. Drake (1995), Role of near-bed turbulence structure in bed load transport and bed form mechanics, Water Resour. Res., 3, 2071-2086.

Nelson, P. A., J. G. Venditti, W. E. Dietrich, J. W. Kirchner, H. Ikeda, F. Iseya, and L. S. Sklar (2009), Response of bed surface patchiness to reductions in sediment supply, J. Geophys. Res., 114, F02005, doi:10.1029/2008JF001144.

Nepf, H. M. (1999), Drag, turbulence, and diffusion in flow through emergent vegetation, Water Resour. Res., 35, 479-489.

Nitsche, M., D. Rickenmann, J. M. Turowski, A. Badoux, and J. W. Kirchner (2011), Evaluation of bedload transport predictions using flow resistance equations to account for macro-roughness in steep mountain streams, Water Resour. Res., 47, W08513, doi:10.1029/2011WR010645.

Papanicolaou, A., P. Diplas, C. Dancey, and M. Balakrishnan (2001), Surface roughness effects in near-bed turbulence: Implications to sediment entrainment, J. Eng. Mech., 127(3), 211-218.

Parker, G. (1990), Surface-based bedload transport relation for gravel rivers, J. Hyd. Res., 28, 417-436.

Parker, G. (2008), Sedimentation Engineering: Processes, management, modeling and practice, Chapt. 3: Transport of gravel and sediment mixtures, edited by M. H. Garcia, ASCE, Virginia, 165-252.

Parker, G., P. C. Klingemen, and D. L. McLean (1982), Bedload and size distribution in paved gravel-bed streams, J. Hydraul. Eng., 108, 544-571.

Rajaratnam, N., and M. R. Chamani (1995), Energy loss at drops, J. Hydraul. Res., 33, 373-384.

Recking. A. (2009), Theoretical development on the effects of changing flow hydraulics on incipient bed load motion, Water Resour. Res., 45, W04401, doi:10.1029/2008WR006826.

Rice, C. E., K. C. Kadavy, and K. M. Robinson (1998), Roughness of loose rock riprap on steep slopes, J. Hyd Eng. 124, 179-185.

Rickenmann, D. (1997), Sediment transport in Swiss torrents, Earth Surf. Processes Landforms, 22, 937-951.

Rickenmann, D., and B. W. McArdell (2007), Continuous measurement of sediment transport in the Erlenbach stream using piezoelectric bedload impact sensors, Earth Surf. Processes Landforms, 32, 1362-1378.

Rouse, H. (1943), Discussion of Moore (1943), Trans. Am. Soc. Civ. Eng., 108, 1383-1387.

Ryan, S. E., L. S. Porth, and C. A. Troendle (2005), Coarse sediment transport in mountain streams in Colorado and Wyoming, USA, Earth Surf. Processes Landforms, 30, 269-288, doi:10.1002/esp.1128

Schmeeckle, M. W., J. M. Nelson, and R. L. Shreve (2007), Forces on stationary particles in near-bed turbulent flows, J. Geophysical Res., 112, F02003.

Shvidchenko, A. B., and G. Pender (2000), Flume study of the effect of relative depth on the incipient motion of coarse uniform sediments, Water Resour. Res., 36(2), 619-628.
Shvidchenko, A. B., G. Pender, and T. B. Hoey (2001), Critical shear stress for incipient motion of sand/gravel streambeds, Water Resour. Res., 37(8), 2273-2283.

Sklar, L. S., W. E. Dietrich, E. Foufoula-Georgiou, B., Lashermes, and D., Bellugi (2006), Do gravel bed river size distributions record channel network structure?, Water Resour. Res., 42, W06D18 doi:10.1029/ 2006WR005035.

Stock, J. D., and W. E. Dietrich (2003), Valley incision by debris flows: Evidence of a topographic signature, Water Resour. Res., 39(4), 1089, doi:10.1029/2001WR001057.

Thompson, S. M., and P. L. Campbell (1979), Hydraulics of a large channel paved with boulders, J. Hydraul. Res., 17, 341-354.

Thorne, C. R., and L. W. Zevenbergen (1985), Estimating mean velocity in mountain rivers, J. Hydraul. Eng., 111, 612-624.

Tucker, G. E., and K. X. Whipple (2002), Topographic outcomes predicted by stream erosion models: Sensitivity analysis and intermodel comparison, J. Geophys. Res., 107(B9), 2179, doi:10.1029/2001JB 000162.

Turowski, J. M., and D. Rickenmann (2011), Measuring the statistics of bedload transport using indirect sensors, J. Hydraul. Eng., 137, 116-121.

Turowski, J. M., E. M. Yager, A. Badoux, D. Rickenmann, and P. Molnar (2009), The impact of exceptional events on erosion, bedload transport and channel stability in a step-pool channel, Earth Surf. Processes Landforms, 34, 1661-1673, doi:10.1002/esp.1855.

Wallerstein, N. P., C. V. Alonso, S. J. Bennett, and C. R. Thorne (2002), Surface wave forces acting on submerged logs, J. Hydraul. Eng., 3, 349353.

Wathen, S. J., R. I. Ferguson, T. B. Hoey, and A. Werrity (1995), Unequal mobility of gravel and sand in weakly bimodal river sediments, Water Resour. Res., 31, 2087-2096.

Whiting P. J., J. F. Samm, D. B. Moog, and R. L. Orndorff (1999), Sediment-transporting flows in headwater streams, GSA Bull., 11, 450-466.

Wiberg, P. L., and J. D. Smith (1991), Velocity distribution and bed roughness in high-gradient streams, Water Resour. Res., 27, 825-838.

Wilcock, P. R. (1993), Critical shear stress of natural sediments, J. Hydraul. Eng., 119, 491-505.

Wilcock, P. R., and J. C. Crowe (2003), Surface-based transport model for mixed-size sediment, J. Hydraul. Eng., 129, 120-128.

Wilcock, P. R., and J. B. Southard (1988), Experimental study of incipient motion in mixed-size sediment, Water Resour. Res., 24, 1137-1151.

Wilcox, A. C., E. E. Wohl, and J. M. Nelson (2006), Flow resistance dynamics in step-pool channels: 2. Partitioning between grain, spill and woody debris resistance, Water Resour. Res., 42, W05419, doi:10.1029/ 2005WR004278.

Wohl, E., and D. M. Thompson (2000), Velocity characteristics along a small step-pool channel, Earth Surf. Processes Landforms, 25, 353-367.

Yager, E. M. (2006), Prediction of sediment transport in steep, rough streams, Ph.D. dissertation, Univ. of California, Berkeley.

Yager, E. M., J. W. Kirchner, and W. E. Dietrich (2007), Calculating bedoad transport in steep boulder bed channels, Water Resour. Res., 43, W07418, doi:10.1029/2006WR005432.

Zimmermann, A. (2010), Flow resistance in steep streams: An experimental study, Water Resour. Res., 46, W09536, doi:10.1029/2009WR 007913.

Zimmermann, A. and M. Church (2001), Channel morphology, gradient profiles and bed stresses during flood in a step-pool channel, Geomorphology,

Zimmermann, A., M. Church, and M. A. Hassan (2008), Identification of steps and pools from stream longitudinal profile data, Geomorphology, 102, 395-406, doi:10.1016/j.geomorph.2008.04.009.

W. E. Dietrich and J. W. Kirchner, Earth and Planetary Science Department, University of California at Berkeley, 307 McCone Hall, Berkeley, CA 94720-4767, USA.

J. W. Kirchner and B. W. McArdell, Swiss Federal Institute for Forest, Snow and Landscape, Zürcherstrasse 111, CH-8903 Birmensdorf, Switzerland.

E. M. Yager, Center for Ecohydraulics Research, Civil Engineering Department University of Idaho, 322 E. Front St., Suite 340, Boise, ID 83702,USA. (eyager@uidaho.edu) 